\title{
Modeling trauma in rats: similarities to humans and potential pitfalls to consider
}

\author{
Birte Weber ${ }^{1 \dagger}$, Ina Lackner ${ }^{1 \dagger}$, Melanie Haffner-Luntzer ${ }^{2}$, Annette Palmer ${ }^{3}$, Jochen Pressmar ${ }^{1}$, \\ Karin Scharffetter-Kochanek ${ }^{4}$, Bernd Knöll ${ }^{5}$, Hubert Schrezenemeier ${ }^{6}$, Borna Relja ${ }^{7,8}$ and Miriam Kalbitz ${ }^{1 *}$
}

\begin{abstract}
Trauma is the leading cause of mortality in humans below the age of 40 . Patients injured by accidents frequently suffer severe multiple trauma, which is life-threatening and leads to death in many cases. In multiply injured patients, thoracic trauma constitutes the third most common cause of mortality after abdominal injury and head trauma. Furthermore, $40-50 \%$ of all trauma-related deaths within the first $48 \mathrm{~h}$ after hospital admission result from uncontrolled hemorrhage. Physical trauma and hemorrhage are frequently associated with complex pathophysiological and immunological responses. To develop a greater understanding of the mechanisms of single and/or multiple trauma, reliable and reproducible animal models, fulfilling the ethical 3 R's criteria (Replacement, Reduction and Refinement), established by Russell and Burch in 'The Principles of Human Experimental Technique' (published 1959), are required. These should reflect both the complex pathophysiological and the immunological alterations induced by trauma, with the objective to translate the findings to the human situation, providing new clinical treatment approaches for patients affected by severe trauma. Small animal models are the most frequently used in trauma research. Rattus norvegicus was the first mammalian species domesticated for scientific research, dating back to 1830. To date, there exist numerous well-established procedures to mimic different forms of injury patterns in rats, animals that are uncomplicated in handling and housing. Nevertheless, there are some physiological and genetic differences between humans and rats, which should be carefully considered when rats are chosen as a model organism. The aim of this review is to illustrate the advantages as well as the disadvantages of rat models, which should be considered in trauma research when selecting an appropriate in vivo model. Being the most common and important models in trauma research, this review focuses on hemorrhagic shock, blunt chest trauma, bone fracture, skin and soft-tissue trauma, burns, traumatic brain injury and polytrauma.
\end{abstract}

Keywords: Trauma research, Comparability, Translational research, Rat model, Translation pitfalls, Polytrauma

\section{Background}

Trauma is the leading cause of mortality in humans aged below 40 in high-income countries [1,2]. Patients involved in severe accidents frequently suffer more than one severe traumatic insult, which is also described multiple trauma or polytrauma. Polytrauma is defined as significant injuries of three or more points on the

*Correspondence: miriam.kalbitz@uniklinik-ulm.de

${ }^{\dagger}$ Birte Weber and Ina Lackner first authors contributed equally to this work

${ }^{1}$ Department of Traumatology, Hand-, Plastic-, and Reconstructive Surgery, Center of Surgery, University of UIm Medical School,

Albert-Einstein-Allee 23, 89081 Ulm, Germany

Full list of author information is available at the end of the article abbreviated injury scale (AIS) in two or more different anatomic abbreviated injury scale (AIS) regions in conjunction with one or more additional variables from the following five physiologic parameters: age, hypotension, unconsciousness, acidosis and coagulopathy [3]. In multiply injured patients, thoracic trauma constitutes the third most frequent cause of mortality after abdominal injury and head trauma [4]. Furthermore, $50 \%$ of all trauma-related deaths within the first $48 \mathrm{~h}$ after hospital admission result from an uncontrolled hemorrhage [5]. Physical trauma is frequently associated with a complex immunological response [6] and overwhelming activation of the complement system as well as the associated release of pro- and anti-inflammatory mediators [7]. To 
model this complex interplay, reliable in vivo systems are required. Basic scientific approaches in trauma research range from zebra fish to nonhuman primates $[8,9]$.

Small animal models are most frequently used in trauma research, with the aim to improve and develop a basic understanding of the complex posttraumatic regenerative and inflammatory mechanisms. When modeling trauma in rats, adequate analgesia and anesthesia is applied to comply with ethical fundamentals. Furthermore, researchers have to consider that any, even very limited, mental stress or pain could compromise the experimental results and quality of scientific findings and, therefore, have consequently to be eliminated [10]. Post-surgical pain is normally attenuated by opioid analgesics, including buprenorphine and transdermal fentanyl administration $[11,12]$.

There are multiple rat trauma models, dealing with different injury patterns, including hemorrhagic shock (HS), chest trauma, bone fractures, tissue trauma, burn injury, traumatic brain injury (TBI) or any combination thereof [13-19]. In polytrauma rat models, different single traumata are combined dependent on the objective of the investigation. According to the continuously increasing numbers of rat trauma studies in medline-listed publications, using rats for trauma modeling is well accepted by the scientific community. Rat models have become a powerful tool for research on many aspects of trauma. The most frequently used rat strains, all outbred, are Sprague-Dawley in modeling multiple trauma, TBI, concussion, HS, long bone fracture and blunt chest trauma, followed by Wistar and Long Evans strains.

The search engine of the National Library of Medicine, pubmed, displayed 61213 (September 2018) results for "rat and trauma". Rattus norvegicus was the first mammalian species domesticated for scientific research, dating back 1830 [20]. In 1903, Bateson used rats to demonstrate that rat fur color obeys Mendelian laws [20]. In biomedical research, rats became the most frequently studied animal model [21]. One of the first genetic studies was performed in rats [22]. The first rat inbred strain was established by King in 1909 [23]. Presently, there are more than 200 inbred strains of $R$. norvegicus available [24]. The rat genome was the third complete mammalian genome deciphered. Comparison to the human genome revealed that while the rat genome encodes a similar number of genes, this genome (2.75 gigabases, $\mathrm{Gb})$ is smaller compared to the human genome $(2.9 \mathrm{~Gb})$. However, there are some important further differences. Humans have 23 pairs of chromosomes, whereas rats have 21 [25]. All human genes known to be associated with disease have corresponding orthologues in the rat genome, but their rates of synonymous substitution are significantly different in the remaining genes. The overall orthologues genomic regions in rats and humans correspond to $46 \%$, whereas the 'disease orthologous regions' correspond to 76\% [25]. Regarding immune-system diseases, studies of the respective rodent genes are less relevant compared to other pathophysiology disease systems, because of the rapid diversification of functions of the immune systems of rodents and humans [25]. Even so transgenic modifications in the rat genome allowed an opening of the rat genomic tool box and provided new opportunities to mimic human pathologies and diseases in rats, including hypertension, atherosclerosis, HIVrelated pathologies and Huntington's disease [26].

The Glue Grant Program has improved our understanding about how humans respond to injuries [27]. This program includes data sets of the genomic and proteomic responses to serious, potentially lethal injuries, which were analyzed mainly in the plasma of trauma and burn patients [27]. These findings enable a better modeling of organ failure, predictions for a patient's outcome and the development of new therapeutics. Nevertheless, there exist anatomic, physiologic and pathophysiologic differences between rats and humans, which have to be considered when planning and interpreting rat trauma models in translational research, particularly when in combining single trauma models [28]. With the aim to increase translational success in trauma research, this review aims to highlight similarities and differences of rats and humans with regard to trauma.

\section{Coagulation system}

The blood coagulation system of the rat has long been investigated. Because this system is extremely rapid in the rat, this special property was used for the application of a specific rodenticide, influencing and acting on the coagulation system by disrupting vitamin K metabolism [29, 30]. Since 1948, the compound 'warfarin' has been successfully marketed as a rodenticide. Later, this substance was used as a therapeutic anticoagulant in the clinic and was preferred to other anticoagulants because of its special and beneficial properties. Therefore, the substance was approved as a therapeutic substance for humans in 1954 [29].

In humans, severe hemorrhage following trauma accounts for $40-50 \%$ of deaths $[5,31]$. During the resuscitative phase, warmed intravenous fluid administration, appropriate transfusion of blood and blood products in combination with surgical control of life-threatening hemorrhage and damage control operations supplemented by angiographic bleeding control is performed according to the Advanced Trauma Life Support (ATLS) guidelines in humans. Trauma-induced coagulopathy (TIC) has been shown to increase with the injury severity score (ISS) [32]. Furthermore, acute traumatic 
coagulopathy (ATC) dramatically increases the blood loss during trauma. ATC develops very rapidly within the first 60 min after trauma and is also associated with increased patient mortality [33-35]. An animal model of ATC was developed in Sprague-Dawley rats, mimicking the specific clinical scenario [36]. ATC in this rat model was similar to human ATC in terms of temporality, type of injuries, compensation mechanisms and coagulation impairments. Moreover, compensatory mechanisms, maintaining blood pressure and homeostasis were similar in this model in rats and humans [36]. In both rats and humans, the Bezold-Jarisch reflex is activated after ATC, increasing end-diastolic volumes and cardiac output [36, 37]. During ATC, values for the activated partial thromboplastin time ( $\mathrm{aPTT})$ and prothrombin time $(\mathrm{PT})$ are comparable between rats and humans $[35,36]$. However, quantitative results in blood coagulation are not transferable between rats and humans because of speciesspecific differences in concentrations of certain clotting factors in the serum [36]. Coagulopathic bleeding needs to be addressed by restoring normal hemostatic physiology. In humans, the PT, aPTT, thrombin time (TT) and fibrinogen concentration are screening parameters to evaluate the main coagulation pathways [38]. By comparing clotting factors and fibrinolytic parameters in human plasma and samples from rats and other animals, fibrinogen, alpha 2 antiplasmin and antithrombin III were in the range of human plasma. By contrast, coagulation factor (F)V, FII, FXII and FXIII in rats were elevated while FVIII, XI, X and XI were reduced compared to pooled human citrated plasma from healthy donors [39]. The platelet count in rats ranges between 500 and $1.300 \times 10^{9} / \mathrm{L}[40,41]$ compared to only $150-400 \times 10^{9} / \mathrm{L}$ in humans [42]. Regarding rotation thromboelastometry (ROTEM) parameters, the clotting time (CT) without thrombin stimulation is three-times longer in humans (595 s) compared to rats (207 s) [43]. Thromboelastometry in a non-activated thromboelastometry (TEM) test also displayed a shorter clot formation time (CFT) and longer maximum clot firmness (MCF) parameters in rats compared to humans [43]. Moreover, platelets were at least four-times less responsive to thrombin compared to humans when aggregometry was used [44]. Furthermore, in an experiment with controlled HS in Sprague-Dawley rats, a prolongation of the plasmatic $\mathrm{PT}, \mathrm{aPTT}$ and $\mathrm{CTs}$ indicated for early and progressive hypocoagulopathy after controlled hemorrhage and shock [45]. Thereby, the early hypocoagulopathy was found to be a two-step process, with platelet dysfunction first followed by fibrinogen impairment, which is also similar in humans [45-47]. Lemini et al. evaluated gender differences in Wistar rats, and coagulation analyses demonstrated differences in the PT, aPTT, TT and fibrin values [48]. Similarly, gender differences in the coagulation system have been shown in humans [49]. Furthermore, posttraumatic analgesia, including buprenorphine, has been shown to interact with the coagulation system: buprenorphine analgesia has been shown to be associated with coagulopathy and increased plasma fibrinogen in healthy rats [12]. Moreover, when modelling blood coagulation in rats, differences in the coagulation system of different rat strains should be carefully considered. Rats of the Fisher and Wistar strains were demonstrated to develop severe hemorrhage in various organs after being fed a vitamin K-deficient diet, in contrast to Sprague-Dawley rats, which did not develop severe hemorrhaging. The animals with severe hemorrhaging displayed abnormal symptoms, including weakness, bloody urine and paralysis [50].

Therefore, because of the extensive species-specific differences between humans and rats, the research on blood coagulation is limited. Although there are some differences, including concentrations of coagulation factors in the serum, platelet count and platelet responsiveness to thrombin, the rat represents a good model for studying trauma-induced coagulopathy because of the highly relevant comparability to the human coagulation system. However, some species-specific limitations in the coagulation system of rats, including the CT, CFT and MCF, need to be considered for a high level of clinical transferability of the model. Summary of modeling the coagulation system in rats is provided in Box 1.

\section{Hemorrhagic shock (HS)}

A total of $3161(09 / 2018)$ pubmed articles were found while searching "rat hemorrhagic shock". Of these studies, $80 \%$ used male rats, $2 \%$ females and $18 \%$ of unknown gender. Regarding the technique used to induce and maintain HS the majority of the studies were performed by tail-tip amputation. Furthermore, uncontrolled hemorrhage was investigated in different rat models: tail-cut and liver punch biopsy correlated best with class I shock, whereas liver laceration and spleen transection models correlated best with class II shock. Although the anesthesia and analgesia applied in all models had an impact, the heart rate declined in all models throughout the experiment [13]. HS was kept pressure controlled, volume controlled or uncontrolled [51]. For resuscitation, there exist several different protocols, including re-transfusion of shed blood, supplementary infusion of Ringers lactate, saline, hydroxyethyl starch (HES) or any combination thereof [52]. For blood withdrawal and monitoring of the arterial blood pressure HR, arterial catheters can be readily implanted. Here, femoral vessels, the carotid artery or jugular vein are frequently used [53]. In contrast to humans [54], during the HS state in rats, the HR did not increase $[55,56]$. Therefore, Choi et al. used a coefficient 


\section{Coagulation System}

Aspects to consider:

- Coagulation factors (F)V, FII, FXII and FXIII are elevated and FVIII, XI and X are reduced in rat plasma compared to humans

- Platelets in rats range between $500-1300 \times 10^{9} / \mathrm{L}$ and platelets in humans between $150-400 \times 10 \% / \mathrm{L}$

- Clotting time (CT) in rats is $207 \mathrm{sec}$ and $595 \mathrm{sec}$ in humans

- Rats have shorter clot formation time (CFT) and longer maximum clot firmness (MCF) compared to humans

- Platelets of rats are four-fold less responsive to thrombin compared to humans

Beneficial characteristics:

- The levels of fibrinogen, alpha 2 antiplasmin and antithrombin III in plasma are comparable between humans and rats

- Gender differences in prothrombin time (PT), activated partial thromboplastin time (aPTT), thrombin time (TT) and fibrin values in rats, which are similar to humans

- Early hypocoagulopathy after controlled hemorrhagic shock occurs in a two-step process (platelet dysfunction, followed by fibrinogen impairment) which is similar to humans

Practical hints, analgesia and anesthesia:

- Model for acute traumatic coagulopathy (ATC) in Sprague Dawley rats

- Modeling early hypocoagulopathy in Sprague Dawley rats

- Caution: Buprenorphine analgesia increases plasma fibrinogen in healthy rats!

Box 1 Summary of aspects to consider and beneficial characteristics as well as of practical suggestions, analgesia and anesthesia for modeling the coagulation system in rats

of the lactate concentration and peripheral perfusion to estimate the shock state in rats [55]. Reynolds et al. described a novel comparative hemorrhagic model of shock vulnerability, which was quantified by so-called 'vulnerability curves.' In this model, HS was induced incrementally and the physiological response to hemorrhage was determined by measuring the relative changes from the baseline of the cumulative blood volume, mean arterial pressure (MAP) and oxygen delivery $\left(\mathrm{DO}_{2}\right)$ during constant-rate hemorrhage, continued to cardiovascular collapse. Here, the lactate level is mostly independent of the rat strain (Wistar-Kyoto, Sprague-Dawley) [57]. However, Reisz et al. measured systemic levels of lactate and succinate in different species and found significantly higher levels in rats than in non-human primates and humans after HS [58]. Furthermore, there are reports of inter-strain variability in rats, which have to be considered in relation to HS experiments. The $\mathrm{PaCO}_{2}, \mathrm{PaO}_{2}$, oxygen content, potassium, sodium, base excess and lactate in arterial blood measurements during HS were described to differ significantly among five investigated rat strains (Brown Norway Medical College of Wisconsin, Fawn Hooded Hypertensive, Dahl Salt-Sensitive, Dark Agouti and Lewis rats) [59]. In accordance with this, earlier studies similarly revealed strain-dependent differences in the survival time after HS in rats. Therefore, the selection of the rat strain for HS studies must be considered [60, 61].

Troy et al. investigated the role of cardiac vagal and cardiac spinal signals in triggering bradycardia and decompensation during HS in rats and found that cardiac spinal signals play an important role in the triggering and progression of the decompensatory response to hemorrhage [62]. In addition to myocardial autonomic dysfunction during HS, increased cardiac endothelial nitrogen oxide synthase (NOS) expression in rats was found to regulate the HR after blood loss [63]. Furthermore, inhibitors of $\mathrm{H}_{2} \mathrm{~S}$ biosynthesis, including glibenclamide, partially restored the HR during HS in rats [64]. When working with rats as a model of HS, the nutritional status of the animals should be considered. Following HS, the enteral microbiome is described as an important source of bacterial endotoxemia and developing sepsis, which depends presumably on the chow of the animals [65]. Germ-free animals displayed a significantly higher survival rate $72 \mathrm{~h}$ after HS compared to conventional animals [66]. Additionally, anesthesia method appears to play an important role in executing a HS model in rats: some study groups decided to perform a thoracic epidural anesthesia in rats, because it increased mucosal perfusion of the intestine. Furthermore, this technique also prevented systemic acidemia and increased leucocyte rolling after hypotension, which should be considered when implementing a realistic trauma model in rats [67]. Following HS, the intestinal perfusion flow was also dependent on the gender of the rats, because the perfusion was significantly decreased in males after HS compared to female rats [68]. In agreement with this, Li et al. [69] described that (pre-menopausal) women and female rats displayed a lesser decrease in vascular responsiveness after traumatic shock than older men and rats of the same age, respectively. In pigs, the reactivity of renal vessels was impaired 
after HS, whereas in rats it increased slightly in the early phase of shock and subsequently decreased gradually [70, 71]. Summarizing, the critical point of HS studies is frequently the microvascular response, which varies across animal species, between the sexes and observed organs and because of factors like anesthesia. Taken together, for studying trauma-induced HS, rat models offer many advantages. Because of the high level of rat model standardization and their large blood volume, the blood pressure and volume can be monitored during hemorrhage, leading to reliable results and reduced standard deviations. Additionally, their large blood volume allows a continuous hemodynamic monitoring as well as repetitive and detailed blood analysis. Moreover, it is technically relatively easy in rats to insert catheters to monitor the level of hemorrhage because of their large and anatomically readily accessible vessels. However, an appropriate HS model in rats should be chosen with deliberation and must be adapted to the aim of the study, particularly because of the manifold variables that influence the microvascular response after blood loss. Summary of modeling hemorrhagic shock in rats is provided in Box 2.

\section{Blunt chest trauma}

Approximately $25-50 \%$ of all injuries involve thoracic trauma [72]. The most frequently used small animal models for blunt chest trauma are captive bolt handgun [14], weight drop (maximum energy equivalent $2.45 \mathrm{~J}$, mortality 33\%) [73] and blast wave [74-76], resulting in pulmonary contusion and in systemic and local inflammation. To prevent an associated cardiac injury, in weight-drop models an additional protective shield is utilized [73,77], whereas cardiac injuries can be detected in models induced by blast wave [78]. Functionally, correlation between the volume of the lung contusion and dysfunction are similarly limited in rats and humans $[79,80]$. Clemedson and Pettersson already described in 1953 the mechanical forces that are relevant for lung contusion, with subsequently disrupted alveoli and small airways by shearing forces as well as for stripping of alveolar tissue from heavier hilar structures, caused by acceleration at different rates [81]. Increased cytokine and chemokine concentrations in bronchoalveolar lavage fluid (BAL) have been found after trauma in rats as well as in the human situation [73, 82, 83]. Neutrophil infiltration was detected in lung tissue in rats after blast injury [74], whereas neutrophil depletion significantly reduced lung injury based on BAL albumin concentrations post contusion [73]. Furthermore, chemotactic and phagocytic activity of alveolar macrophages was increased after blunt chest trauma, which is again similar to humans [82, 84]. Modeling blunt chest trauma in rats is well defined and standardized, however, there are some differences between rats and humans to be considered when interpreting data. One divergence is based on differences in toll-like receptors (TLRs) and thus in the recognition of endotoxins and damage-associated molecular patterns (DAMPs) [85]. In the extracellular domain of TLR4, humans and rats share only $61 \%$ total amino acid similarity [86]. Moderate levels of TLR4 expression were detected in human lungs, whereas human alveolar epithelial type II cells and alveolar macrophages have been shown to mainly express TLR2 [87]. In contrast

\section{Hemorrhagic Shock (HS)}

\section{Aspects to consider:}

- Differences in heart rate adjustment during hemorrhagic shock: in rats heart rate did not increase during HS compared to humans

- Higher levels of lactate in rats than in non-human primates

- Nutritional status influence endotoxemia-depending survival

- Microvascular response is a critical point and differs between species and gender (in males intestine perfusion decreased compared to females)

\section{Beneficial characteristics:}

- Hemodynamic monitoring is uncomplex due to the large blood volume of rats

- Blood pressure and blood volume monitoring is very easy

- Implantation of catheters is technically very easy due to anatomical advantages

- Large blood volume is available for analysis

Practical hints, analgesia and anesthesia:

- Hemorrhagic shock most often performed by tail amputation

- Thoracic epidural anesthesia leads to increased mucosal perfusion of the intestine, prevents acidemia and leucocyte rolling

- Tail cut and liver bunch biopsy = class 1 shock, liver laceration and spleen transection = class 2 shock

Box 2 Summary of aspects to consider and beneficial characteristics as well as of practical suggestions, analgesia and anesthesia for modeling hemorrhagic shock $(\mathrm{HS})$ in rats 
to human dendritic cells (DC), all rat DC subsets and monocytes from Sprague-Dawley, Lewis and Brown Norway rats express TLR4 [85]. Therefore, when using trauma rat models for the prediction of human responses to TLRs agonists, scientists should be aware of the inherent limitations of rat studies. Even the discussed presence of pulmonary intravascular macrophages (PIM) [88], constitutive or inducible in humans and in rats respectively, may contribute to species-dependent differences in the sensitivity to endotoxin-induced lung injury [89]. Additionally, previous data have shown similarities in the histological appearance of CD68-positive intravascular cells in human and rat lungs of hepatopulmonary syndrome [90]. Lipofibroblasts are another cell population known in the lungs of rats (and mice), but is still under debate for human lungs [91]. Furthermore, nitric oxide (NO) is an important mediator of numerous physiologic and inflammatory processes in the lung. Constitutive NOS (cNOS) has been found in human lung nerves and large-vessel endothelium, but was lacking in the airway and alveolar epithelia. In rats, cNOS was found in lung nerves, endothelium and alveolar epithelium [92]. Inducible NOS (iNOS) was expressed in human alveolar macrophages during chronic inflammation and, quite similarly, in rat macrophages after lipopolysaccharide (LPS) treatment [92]. Rat and human neutrophils have been shown to produce comparable amounts of NO, but much less than rodent macrophages [93]. With regard to anatomical differences between rat and human lungs, airway branching in humans is more dichotomous and symmetric, whereas rat lungs are more monopodial [94]. The latter might need to be considered when studying air flow distribution, gas uptake and aspiration. Furthermore, severe blunt chest trauma is also associated with cardiac inflammation and structural alteration of cardiac tissue in rats [78]. Rats with blast wave-induced blunt chest trauma displayed acute cardiac tissue damage as well as increased concentrations of circulating heart fatty acid binding protein (H-FABP). Furthermore, rats exhibited increased local cardiac inflammation by increased interleukin (IL)-1 $\beta$ levels as well as disturbed cardiac gapjunction architecture [78]. Moreover, increased blood levels of the N-terminal pro-B-type natriuretic peptide after blunt chest trauma in rats was correlated with a blunt-induced cardiac trauma [95]. However, when modeling cardiac damage after blunt chest trauma, differences between the respective rat strains as well as gender differences within the same rat strain should be carefully considered. Male Sprague-Dawley, Wistar and WistarKyoto rats have low initial serum cardiac troponin I levels, whereas Spontaneous Hypertensive and Fisher rats have high baseline troponin I levels. Furthermore, the baseline troponin I levels differ within the same rat strain between the male and female. Thereby, female rats of the Spontaneous Hypertensive, Sprague-Dawley and Wistar displayed significantly lower troponin I baseline levels compared to the respective male rats. Moreover, testosterone and estrogen levels might also influence the presence of systemic cardiac troponin I. In male Spontaneous Hypertensive rats, the serum troponin I levels significantly increased after castration, whereas in ovariectomized female Spontaneous Hypertensive rats, the systemic troponin I concentrations were significantly reduced [96].

In summary, the rat blunt chest trauma model has a very high translational potential and shares many similarities with human blunt chest trauma, particularly regarding immunological processes and cardiac events. A summary of modeling blunt chest trauma in rats is provided in Box 3.

\section{Bone fracture}

Rats have been used as a model for bone fracture healing since the 1940's [15]. Most frequently, femur or tibia fracture is induced in rats. One difference between femur and tibia fracture in rats is the amount of tissue damage, because the femur is completely surrounded by muscles, whereas the tibia at the medial region is only covered by skin [97]. An advantage of the rat model in fracture healing research is the availability of many well-established, standardized fracture procedures. According to ethical considerations, fracture healing studies at present are mostly performed on stabilized fractures. Bonnares and Einhorn in 1994 first described intramedullary nailing of the femur in small animals [97], which was transferred to tibia bone [98]. Currently, there are many different fixation methods available in rats similar to devices applied in humans: unlocked intramedullary pin, locking nail, intramedullary compression screw, interlocking nails and locking plates as well as external fixators [99]. Fracture models include osteotomy by an open surgical approach and closed models using three-point-bending fracture devices. Another advantage of the rat model is the increasing number of naturally occurring or artificially manipulated strains [100] with genetic variations relevant to bone tissue. Because the skeletal phenotype of different rat strains may significantly influence bone healing, this needs to be particularly considered in models like the spontaneous dwarf rat with growth hormone $(\mathrm{GH})$ deficiency [101] and the Komeda miniature rat Ishikawa caused by mutation in Prkg2 [102]. Furthermore, many disease models are available in rats closely mimicking the clinical situation of delayed fracture healing in humans, for example, ovariectomy of rats to induce post-menopausal osteoporosis and subsequent delayed fracture healing $[103,104]$. 


\section{Blunt chest trauma}

\section{Aspects to consider:}

- Toll like-receptor 4 (TLR4) only share $61 \%$ of total amino acid similarity between humans and rats

- Moderate levels of TLR4 are present in human lungs, whereas rat lungs mainly express TLR2

- In contrast to humans, rat dendritic cells express TLR4

- Lipofibroblasts are present in rat lungs but not in lungs of humans

- Differences in pulmonary intravascular macrophages (PIM) between rats and humans contribute to species-dependent differences in sensitivity to endotoxin-induced lung injury

- Airway branching in humans is more dichotomous and symmetric, whereas rat lungs are more monopodial

\section{Beneficial characteristics:}

- Blunt chest trauma model is well standardized in rats

- Increased cytokine and chemokine concentrations in bronchoalveolar lavage fluid (BAL) after blunt chest trauma in rats and humans

- Increased neutrophil infiltration and increased chemotactic and phagocytic activity of alveolar macrophages after blunt chest trauma in rats and humans

- CD68 positive intravascular cells in rats and humans receiving hepatopulmonary syndrome

- Constitutive nitric oxide synthase (cNOS) and inducible nitric oxidase (iNOS) as important mediators of inflammation in lungs of rats and humans

- Rat and human neutrophils produce comparable amounts of nitric oxide (NO)

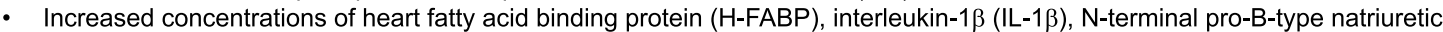
peptide and disturbed cardiac gap-junction-architecture indicating for cardiac injury after blunt chest trauma in rats and humans

Practical hints, analgesia and anesthesia:

- Most commonly used models for blunt chest trauma: captive bolt hand gun, weight drop and blast wave

- Caution when studying responses to TLRs agonists after blunt chest trauma

- Differences in lung architecture should be considered when studying air flow distribution, gas uptake and aspiration

- Modeling of blunt cardiac damage and cardiac injuries

Box 3 Summary of aspects to consider and beneficial characteristics as well as of practical suggestions, analgesia and anesthesia for modeling blunt chest trauma in rats

One disadvantage of the rat model is that its bone structure is more primitive than in humans because of a lack of Haversian systems [99]. However, bone healing in rats via resorption cavities has been shown to be similar to Haversian remodeling in larger animals and humans [105]. Single studies report inter-strain differences in hip fragility of rats, which could influence biomechanical outcome after fracture. Comparison of the femoral bone structure of Copenhagen 2331 rats showed considerable differences in femoral neck structure, bone density and mineral content compared to Dark Agouti rats, despite similar body mass and biomechanical properties at the femoral midshaft and lumbar spine [106]. Such interstrain variabilities of bone structure need further attention in trauma research.

Furthermore, gender [107] and age [108] are important variables for bone research. In rats, bone growth continues much longer after sexual maturity than in humans [109]. In younger rats, fracture consolidation is much more rapid compared to older animals, which corresponds to age-dependent bone healing in humans [110, 111]. When comparing male and female rats of the same age, male animals have a greater body weight, resulting in greater interfragmentary movements at the fracture site. In rats, the bone-healing process is completed within 5 to 6 weeks [112] and is highly dependent on biomechanical conditions of fracture stabilization, as was also shown in humans [113].

Taken together, when studying bone fracture healing in rats, there are several surgical techniques available. An increasing number of genetic manipulations in rats affecting skeletal phenotype allows more specific investigations. However, rat strain, age and gender should be considered critically. Overall, rat disease models, like ovariectomy and enhanced age, clearly demonstrated that the rat is able to mimic pathological processes in patients to a close extent, and is, therefore, a valuable tool to gain a deeper understanding of the complex bone-healing process [103, 104], although bone structure differs from humans. A summary of modeling bone fracture in rats is provided in Box 4.

\section{Skin and soft-tissue trauma}

Trauma is frequently associated with damage of skin and soft tissue. There is an enormous difference between the humans and rats, particularly in skin appearance [114]. Rats' skin clearly has little similarity with humans. The rat was also described as a "loose skinned animal" [16], because of the very limited adherence strength to the structures below and the skin's elasticity [114]. Additionally, rats are able to convert $\mathrm{L}$-gluconogammalactone to vitamin C. Vitamin C is very important for the synthesis 


\section{Bone fracture}

\section{Aspects to consider:}

- Limitations in skeletal phenotype and bone structure: primitive bone structure without Haversian systems

\section{Beneficial characteristics:}

- Model for analysis of postmenopausal osteoporosis (ovariectomy) and delayed fracture healing (growth hormone deficiency)

- Increasing number of genetic manipulations possible

- Well reflect the human situation of age dependent bone healing (in young rats faster than in old)

\section{Practical hints, analgesia and anesthesia:}

- Well-established standardized fracture procedures: osteotomy or closed 3-point-bending fracture

- Fixation methods: unlocked intramedullary pin, locking nail, intramedullary compression screw, interlocking nails, locking plates

Box 4 Summary of aspects to consider and beneficial characteristics as well as of practical suggestions, analgesia and anesthesia for modeling bone fracture in rats

of collagen and, therefore, also for wound and soft-tissue healing. Furthermore, the epidermis and the dermis of rats are thinner than in humans, which could be challenging for suturing. Interestingly, rats are frequently used as a special model for a part of the complex system of wound healing in humans: wound contraction. "Wound contraction is considered to be the primary healing method of rats as opposed to re-epithelialization seen in humans" [16]. The panniculus carnosus muscle is responsible for wound contraction and collagen formation in rats [114, 115]. Furthermore, the risk of wound infection is lower in rats compared to humans because of the reduced healing time [16]. In skin and soft-tissue trauma, differences in rat strains were observed between Brown Norway, Lewis and Wistar rats. Thereby, the different rat strains displayed variations in the severity of skin lesion after exposure to hexachlorobenzene, which was associated with activation of the immune system in the respective rat strain [116].
Taken together, rats could be used as trauma models for very specific questions regarding skin and tissue traumas. However, several limitations, as mentioned above, should be considered when rats are used for wound-healing studies to ensure valid and reliable results. A summary of modeling skin- and soft tissue trauma in rats is provided in Box 5 .

\section{Burn injury}

Burn injury is one of the most weakening traumas affecting humans. According to the World Health organization (WHO), more than 300,000 deaths globally are caused annually by burns [117]. For investigation of burn injuries in rats, various burn injury rat models are available. The most frequently used burn model in rats is the scalding burn model. Here it is possible to determine the exact exposed surface area of the skin [16]. The temperature and the immersion time are variable and vary from study to study. The major drawback of this model is that the rat in contrast to human is able to cope with

\section{Skin and soft tissue trauma}

\section{Aspects to consider:}

- Rats are 'loose skinned animals', absence of adherence strength to structures below the skin's elasticity, which is in contrast to human skin

- Rats are able to convert L-gluconogammalactone to vitamin $\mathrm{C}$ in contrast to humans

- Epidermis and dermis of rats are thinner in contrast to human skin

- Risk of wound infection is lower in rats compared to humans due to reduced healing time in rats

\section{Practical hints, analgesia and anesthesia:}

- Clinically highly relevant model for wound contraction analysis

Box 5 Summary of aspects to consider and beneficial characteristics as well as of practical suggestions, analgesia and anesthesia for modeling skin and soft-tissue trauma in rats 
hypermetabolism. Hyperglycemia frequently occurs during the early post-burn phase in humans. Therefore, it could be very complex to induce additional infections in rats, mimicking post-burn sepsis, which frequently occurs in humans [118]. Furthermore, strain differences should be carefully considered when trying to perform lipopolysaccharide (LPS)-induced sepsis in rats. Brown Norway and Lewis rat strains showed different responsiveness to LPS, which was modulated by the liver of the animals [119]. In another full-thickness skin burn model, the temperature and the burned area are variable. The major drawback of this method is the lack of a homogenous uniform burn depth [16]. In another rat burn model, radiant heat was used [120]. In this model, the heating source does not make direct contact with the rat skin and the heat dispersion is very constant. When conducting burn- or wound-healing studies in rats, it should always be critically kept in mind that differences in human and rat skin are also present internally $[16,17]$. This is described in the previous chapter. In conclusion, rat models for studying burn injuries allow specific investigations of local burn injuries, which are of high clinical relevance for traumatic issues. A summary of modeling burn injury in rats is provided in Box 6 .

\section{Traumatic brain injury (TBI)}

Severe injury to the central nervous system (CNS) accounts for a third of all trauma-related deaths followed by CNS injury with additional exsanguination (17\%) [5]. Mild TBI (concussion) occurs most frequently after trauma [121]. The most frequently used methods to initiate TBI in rodents are the lateral fluid percussion injury (LFP), controlled cortical impact (CCI) and weight-drop impact. LFP results in reproducible pathological changes similar to those observed in human head injury [18, 122]. Histopathological findings were subarachnoid and intraparenchymal hemorrhage [122]. Furthermore, CCI reflects a severe form of TBI, with skull deformation and related cortical compression. In this model, mechanical force, velocity and depth of skull deformation can be controlled, and thus it provides important advantages for standardizing research on TBI. The pathological findings are diffuse axonal injury, subdural hematoma, brain edema, elevated intracerebral pressure, reduced perfusion, metabolic changes, blood-brain dysfunction and coma [53].

A weight-drop impact induces both apoptotic and necrotic neuronal cell death by activating proinflammatory mediators, caspases and members of the Bcl-family [123]. A metal cylinder falls from a fixed height (approx. $2 \mathrm{~cm}$ ) onto the dura. The gravitational force induces contusion, cortical cell loss, edema, blood-barrier dysfunction and apoptosis. Histologically, bilateral damage of neurons, axons, dendrites and microvasculature is observable [53, 124].

Another rat model of TBI is the cryogenic injury model, leading to a focal brain lesion [125]. In this model, the brain injury is induced by applying a cold rod to the exposed dura [126]. Different injury severity can be achieved by varying the exposure time of the cortex to the rod [127]. Standardized lesions caused in this model are clearly confined and highly re-producible [125]. However, this model lacks the formation of diffuse axonal injuries, which frequently occur in human brain injuries [128]. Another rat brain injury model, which became increasingly important during recent years, is blast-induced brain injury. Thereby, rats were mainly exposed to blast waves of different intensities, mimicking blast waves caused by explosions [129]. When modeling TBI in rats, differences in rat strains should be carefully considered. The response to injury strongly varies between different rat strains, which might contribute to

\section{Burn injury}

\section{Aspects to consider:}

- Rats are in contrast to humans able to handle hypermetabolism (humans often have post-burn hyperglycemia)

- Variable temperature and burned area due heated metal instruments

- Differences in human and rat skin

Beneficial characteristics:

- Clinically transferable for studying local burn injuries

- Clinical reliable model of burn injuries with post-burn sepsis

Practical hints, analgesia and anesthesia:

- Clinically highly relevant model for wound contraction analysis

Box 6 Summary of aspects to consider and beneficial characteristics as well as of practical suggestions, analgesia and anesthesia for modeling burn injury in rats 
differences in viability among studies. Sprague-Dawley and Fisher rats have received lateral fluid percussion injury. Thereby, Fisher rats exhibited a greater mortality rate and longer duration for regeneration of the righting reflex. Moreover, differences in motor and cognitive abilities after trauma were shown in the two different strains. Thereby, Fisher rats displayed greater motor deficits but performed better in cognitive tests following injury compared to Sprague-Dawley rats. However, Fisher rats showed increased caspase-3 expression, higher intracranial pressure and prolonged seizure activity compared to Sprague-Dawley rats [130].

When modeling TBI, scientists frequently analyze behavioral reactions [131]. However, there are differences between rodents and humans concerning physiological and behavioral responses to TBI [132]. The rodent brain is inappropriate for representing the more complex human cortex. Although there are many differences in brain anatomy and complexity, there are also some analogies, for example, in cerebrovascular parameters [123]. Cordeiro et al. highlighted that the human brain ratio of white:gray matter differs from rats; because the amount of white matter is significantly smaller [133]. Codeiro et al. additionally indicated that human intracerebral hemorrhage is neither an insult at a single spot in the brain nor restricted to one anatomical region. However, the induced traumata only inflicted one region in the brain, which differs from a real traumatic injury [133]. Rats' brain edema reaches the full extension within a few days of brain injury, whereas in humans, brain edema persists for weeks [133]. There are many well-established neurological tests, including the Morris water maze and the Open-Field-Test, which are applicable to rats based on their capability to learn quickly. Following concussion, the activity of exploration is significantly reduced [134]. Furthermore, Eakin et al. described mice as swimming more poorly than rats, giving rats a clear advantage in different research settings. Sham animals of this study performed significantly better in neurological tests than animals with a weight-dropped-induced TBI [135]. The play fight behavior was significantly reduced in animals with concussion. The male rats with TBI decreased their play fight regardless of their mates' conditions. By contrast, female rats initiate less social interaction with mates with TBI. This ability to interpret emotions and behavior is located in the frontal lobes of the brain, which is a common target of concussion in humans. The elevated female sensitivity might lead to a greater risk for depression, anxiety and loneliness after TBI [136]. The Open-Field-Test is particularly designed for rats and observes the spontaneous intension of exploration. The animal is placed in a box, movements are monitored by a video camera and the overall distance travelled in a defined time period is automatically quantified. Following concussion, the activity of exploration is significantly reduced [134].

Traumatic brain injury is associated with a neuroinflammatory response involving brain-resident immune cells, including microglia and reactive astrocytes present at the impact site $[137,138]$. In this cellular response, similarities between human and rat TBI were described. For example, microglia activation, involved in the clearing of myelin debris, occurs both in rats and humans [139-142]. A difference between human and rat TBI might exist with regard to the duration of the neuroinflammatory response. In the rat, while neuroinflammation occurs early after TBI, this response is rather transient, whereas after human TBI, microglial activation can persist for several years [141, 142]. Microglia and other immune cells in the TBI impact site are known to secret interleukins, chemokines and other factors $[137,138]$. In this cellular response, similar expression of selected molecules, including interleukins (IL-18) and tissue inhibitor of metalloproteinase 1 (TIMP-1), were reported in both human and rat TBI [143-145]. Therefore, although differences in TBI-associated cytokine and chemokine profiles might exist between humans and rodents, some molecular patterns are conserved.

An important aspect in TBI research is the identification of prognostic biomarkers from, for example, blood and cerebrospinal fluid samples. Interestingly, in human and rat TBI fluid samples, a similar biomarker profile was observed [146, 147]. This included proteins like Tau, S100B and glial fibrillary acidic protein (GFAP). Given these similarities, rat TBI models offer the opportunity to identify cellular sources and time courses of biomarker secretion and allow for the correlation of biomarker expression with functional recovery progression after TBI.

TBI is associated with several comorbidities in the years that follow the initial TBI event. These include enhanced frequency of neurodegenerative diseases, for example, Alzheimer's disease, but also epileptic seizures [148]. Here, animal models, including rat TBI models, allow for experimental strategies to determine the cellular and molecular interactions between the initial TBI event and, example, subsequent seizures, and thus enable the development of potential therapeutic interventions [149]. The rat is well suited to analyze these interactions, and seizure occurrence is reported in several TBI models $[149,150]$.

An important molecular hallmark initiated by TBIinjured neurons is the induction of gene expression. In particular, rapid (within minutes) induction of so-called immediate early genes (IEGs), like c-Fos and c-Jun, has been reported in several rodent TBI models, including 
rats [151-153]. Because many IEGs encode transcription factors, a subsequent delayed gene expression program is initiated, which might contribute to neuronal protection after TBI. Notably, similar to rats, induction of selected IEGs, including c-Fos and c-Jun, was also reported in postmortem human TBI brain tissue [154-156]. Therefore, from a molecular perspective, gene expression responses in TBI-injured human and rat neurons appear to some extent to be conserved. Such findings, suggesting conserved TBI-associated molecular responses across different species underline the suitability of rodent models to investigate cellular and molecular TBI responses and to test pharmacological options to accelerate postTBI recovery. A summary of modeling TBI in rats is provided in Box 7.

\section{Polytrauma}

Polytrauma is defined as a combination of multiple severe and simultaneous injuries to more than one body region or organ system $[3,157]$. The effects of the combined injuries on the patient are not comparable with a single trauma, and the mortality of patients affected by polytrauma increases significantly [28, 158]. Although certain singular injuries, including severe TBI and hemorrhage, are clearly associated with higher mortality rates, the combination of multiple injuries aggravates further the outcome [159]. This is caused by the complex posttraumatic immune response, which is a key driver of late post-injury complications and fatal outcome rates after trauma [160, 161]. Interestingly, despite improved treatment strategies with regard to traumatic injuries as well as to the posttraumatic immune response, both mortality and disability rates still remain alarmingly high [162]. Therefore, a reliable in vivo model is necessary to investigate the physiological and pathophysiological responses to polytrauma. The most frequently applied in vivo models to addressing polytrauma do not actually represent polytrauma, because they mainly involve two different insults and thus depict double-hit trauma models. Polytrauma in rats can include any combination of burn injury, fracture, hemorrhage, trauma to the extremities and soft-tissue trauma among many others. In a recently established polytrauma rat model, chest trauma, closed head injury, tibiae/femur fracture and soft tissue trauma were combined [28]. In these polytraumatized rats, a significant systemic and intrapulmonary release of cytokines, chemokines and complement anaphylatoxins compared to rats with isolated injuries or selected combinations of injuries have been observed. Therefore, the authors provided evidence that a double-hit trauma model is of limited suitability to represent a clinical polytrauma in patients. Denk et al. included HS to the above described polytrauma model to further increase its clinical relevance, however, the experiments were performed on mice $[163,164]$. The authors described the detection of specific barrier molecules in a murine polytrauma model and in patients after polytrauma, which appeared to be injury-pattern and time dependent. Therefore, this model is useful to assess posttraumatic barrier dysfunction. However, to date, a long-term polytrauma model

\section{Traumatic brain injury (TBI)}

\section{Aspects to consider:}

- Proportion of white/gray matter differ between humans and rats, amount of white matter is smaller in rats compared to humans

- In brain of rats, edema reaches full extension shortly after few days of TBI, while in human brain edema persists for weeks

- Induced traumata to head only inflicted one anatomical region in the brain, which differs from real TBI in humans

- Microglial activation early after TBI in rats, in contrast to humans where microglial activation persists for several years

Beneficial characteristics:

- Reproducible pathological changes of head injury in rats, which are similar to human head injury

- Microglial activation after TBI in humans and rats

- Expression of interleukin-18 (IL-18) and tissue inhibitor metalloproteinase 1 (TIMP-1) after TBI in humans and rats

- Prognostic biomarkers such as Tau, S100B and glial fibrillary acidic protein (GFAP) in cerebrospinal fluid of humans and rats after TBI

- Expression of immediate early genes c-Fos/c-FOS and c-Jun/C-JUN after TBI in humans and rats

\section{Practical hints, analgesia and anesthesia:}

- Most commonly used models for TBI: lateral fluid percussion injury (LFP), controlled cortical impact (CCI) and weight drop impact

- TBI models in rats are highly reproducible and standardized

- Many well-established neurological tests (Morris water maze, Open-Field-Test)

- Investigations of comorbidities of TBI such as Alzheimer's disease and epileptic seizures

- Clinically highly relevant in testing pharmacological options for post-TBI recovery

Box 7 Summary of aspects to consider and beneficial characteristics as well as of practical suggestions, analgesia and anesthesia for modeling traumatic brain injury $(\mathrm{TB})$ in rats 
in rats, which may be applicable, for example, to study complications like organ failure and sepsis, has not been established. Other issues, including the timing of the application of various traumatic injuries, should also be considered. In an interesting double-hit model, burn injury with soft-tissue and gastrointestinal-tract trauma were combined [19]. Unlike many double-hit models, the authors applied the injuries simultaneously in their model, an approach that actually mimics the setting of the polytraumatized patient. They also confirmed that there were differences between the single injuries and polytrauma in the maintenance of blood glucose, body temperature, body weight, hepatic mRNA and circulating levels of tumor necrosis factor, IL- $1 \beta$ and IL- 6 and hepatic endoplasmatic reticulum stress [19]. Therefore, the authors confirmed that models utilizing combinatorial injuries are needed to more accurately model the human condition. Another polytrauma model includes animals that were subjected to a laparotomy plus burn and single puncture of the cecum injuries [165]. The authors concluded from their data that their model of polytrauma is straightforward to perform and highly reproducible, making it a useful model for studying the multifaceted early pathophysiology following polytrauma. Furthermore, they provided evidence that using a double-hit model to represent polytrauma is of limited validity, because the findings again suggest a complex pathophysiological response to polytrauma, and indicate that the mechanisms leading to the development of insulin resistance vary depending upon the type of injury [165]. Interestingly, their data are unlike those found in more severe single-injury models or those observed following the combination of trauma and hemorrhage. Darlington et al. developed a rat model of polytrauma and hemorrhage that is coagulopathic and displays a prolongation of the PT and platelet dysfunction that closely parallels clinical findings in human trauma patients [166]. In their model, polytrauma was induced by damaging the small intestines, the right and medial liver lobes and the right leg skeletal muscle and inducing fracture of the right femur and hemorrhage. Therefore, it remains indisputable that the choice of the appropriate model has to clearly address the scientific question being asked. Additionally, data from some double-hit models, which are termed as "polytrauma"-because they include more than a single injury type, have to be very carefully interpreted when referring to clinical polytrauma.

By contrast the most-described experimental in vivo models in rats barely meet the definition of polytrauma according to an ISS $\geq 16$. Here again, when referring to the human situation, the in vivo model should include three or more traumatic injury patterns, involve lifethreatening injuries, including brain, chest or abdomen injury, and exert an ISS $>15$. While Weckbach et al. and others, as described above, have compared their experimental polytrauma model with different double-hit models, and on the one hand found that the injury pattern matters, while others on the other hand underlined the undeniable relevance of, for example, HS after experimental polytrauma, as demonstrated by Denk et al. in a mouse model. However, there is another important difference compared to the human situation after trauma, which should also be considered when interpreting the data. Contrary to the human situation, experimental polytrauma is performed under controlled conditions without awakening the animals until sampling.

Taken together, many double-hit models but only a few models of polytrauma combining different injury patterns are applied to study and understand the basic pathophysiology of polytrauma. Modeling the complex injury patterns of polytrauma and the subsequent immune response remains both difficult and challenging, because no single animal model is able to fully represent the diversity of polytrauma as observed in the human situation. Importantly, experimental polytrauma models should imply as little injuries as possible to reduce the harm of animals according to the criteria of the Replacement, Reduction and Refinement (3Rs). A summary of modeling polytrauma in rats is provided in Box 8 .

\section{MSC-based cell therapies after trauma}

The rat models which are described in this review are also suitable to study therapeutic intervention in trauma. As an example, we describe the emerging field of cell therapies, in particular the intervention with mesenchy$\mathrm{mal} \mathrm{stem/stroma} \mathrm{cells} \mathrm{(MSC)} \mathrm{or} \mathrm{MSC-derived} \mathrm{effectors.}$

MSC have been widely used in pre-clinical and clinical research studies on immunomodulation as well as protection or regeneration of damaged tissues (e.g. for treatment of graft-versus-host disease, stroke, brain/nerve injury, bone defects, osteoarthritis) [167, 168]. They are promising candidates for regenerating damaged tissue and modulating deregulated immune reactions. MSC from various tissues (bone marrow, adipose tissue, cord blood and others) and various donor types (autologous, allogeneic, xenogeneic) have been used in these studies. Beneficial effects of MSC were observed in many disease models in rats, independently of tissue source or donor type $[169,170]$. The effects of MSC cannot be explained by a single mechanism of action but seem to be mediated by variety of properties of MSC: They can migrate and integrate to the site of tissue injury and respond to DAMPs. MSC can release factors which stimulate the growth and differentiation of neighbouring cells, induce angiogenesis, regulate the development of fibroblasts and endothelial cells, inhibit fibrosis and create 


\section{Polytrauma}

Aspects to consider:
- Long-term polytrauma models in rats to investigate sepsis or organ failure has not been established so far

Beneficial characteristics:

- Various combinations of individual trauma in one model possible: burn injury, fracture, hemorrhage, trauma to the extremities, soft tissue trauma, TBI

- Possibility of answering specific multiple trauma-derived clinical questions

- Highly clinical transferable in studying specific traumatic issues and aspects

- Investigations of multiple trauma effects on the whole animal

Practical hints, analgesia and anesthesia:

- Double-hit trauma model is limited suitable to represent a clinical polytrauma in patients

- Exert the ISS >15: include three or more traumatic patterns, containing life threatening injuries

- Timing of the application of various traumatic injuries should kept in mind (simultaneously)

Box 8 Summary of aspects to consider and beneficial characteristics as well as of practical suggestions, analgesia and anesthesia for modeling polytrauma in rats

an anti-inflammatory, pro-regenerative microenvironment. Paracrine actions include secretion of cytokines, chemokines and extracellular matrix, and release of extracellular vesicles (EV). They can release EVs of various size ranging from exosomes to microvesicles [171]. These EVs contain proteins, organelles, miRNA and mRNA [172, 173]. They constitute an important intercellular communication system. It has been demonstrated that EVs in some models exert similar effects than MSC themselves [171].

Several in vivo studies, including rat models, demonstrated the unique immune privilege of MSC which can facilitate their use in an allogeneic and even xenogeneic setting [174-178]. However, the impact of donor type of MSC on the effects is discussed controversial and might differ depending on other factors. In a rat model it has been demonstrated that different routes of administration and different microenvironments can lead to divergent immunogenicity of allogeneic MSC [179].

The systemic administration of human (h) bone-marrow MSC in a rat model of blunt chest trauma reduced the lung injury score $24 \mathrm{~h}$ after trauma by at least $50 \%$ compared with traumatized rats without MSCs and the MSC treated rats exhibited a lower level of pro-inflammatory cytokines (interleukin [IL]-1B, IL-6) and chemokines (C-X-C motif chemokine ligand 1 [CXCL1], C-C motif chemokine ligand 2 [CCL2]), but a higher tumor necrosis factor alpha induced protein 6 (TNFAIP6) level in the BAL [178]. In this model, hMSCs could not be detected $24 \mathrm{~h}$ after injection into traumatized rats in the peripheral blood and no human Alu sequences were detectable in the blood or in lung tissue [178]. Also other publications on rodent models of acute lung injury suggest that MSC effects are mediated via secretion of TNFAIP6 [18],
IL-1RN [180] or KGF [181] rather than engraftment and differentiation and long-term persistence of these MSCs. Besides the secretion of soluble factors also the release of EVs can contribute to the beneficial effect of xenogeneic MSCs [182, 183]. Effects of EVs have been demonstrated also in other injury models in rats, e.g. TBI [184], nerve injury $[185,186]$, pre-term brain injury $[177,182]$ or burn injury [187].

Many studies confirmed the potential of MSC for bone repair, including a series of rat models (e.g. critical size defects, non-union fractures). Bone repair by MSC has been demonstrated after different routes of administration (locally, mostly with MSC bound to a scaffold [188-192] or systemic injection [193]), different types of MSC (bone marrow or adipose-derived MSCs), ex vivo expanded MSC with/without gene modification (e.g. overexpression of BMP2 [194] or specific micro-RNAs $[195,196])$ and with or without specific pre-differentiation towards the osteoblastic lineage $[197,198]$ and also with MSC-derived supernatant $[199,200]$ or exosomes [201-204].

A meta-analysis of efficacy of MSC in animal models of traumatic brain injury, including different rat strains (Wistar, Sprague-Dawley, Fisher 344), concluded that MSC therapy may improve locomotor recovery after TBI [168]. For neurological motor function, significant differences were observed in terms of MSC donor type and MSC dose [168]. No significant differences were found in terms of route of administration and tissue source [168].

Overall these studies demonstrate that the rat trauma models can also be used to study therapeutic intervention comparing different interventions (intact MSC from different tissues, MSC-derived soluble factors or MSC-derived EVs) administered via different routes. As 
demonstrated in several rat models an allogeneic or even xenogeneic cell therapy approach is feasible, thus allowing pre-clinical evaluation of human MSC intended to be developed for clinical use.

\section{Conclusion}

Many trauma models are available in rats, and because they may closely correspond to the human response to injury, several differences between humans and rats should be carefully considered when modeling trauma. For example, in rats there are limitations in the coagulation system and some divergent reaction to massive blood loss compared to humans. To reproduce lung injury after blunt chest trauma in rats, the high NO production in rodents and the lack of pulmonary intravascular macrophages should be taken into consideration. Furthermore, there are some limitations in wound healing after soft-tissue trauma and burn injury between rats and humans. Additionally, rats display certain differences in bone structure and a more rapid bone-healing process compared to humans. Certainly, rats are a good model for TBI research, on the one hand because the neurological tests suggest a high capability to learn quickly and because of their curiosity. On the other hand, there is a lack of a perceptive faculty in rats. Furthermore, when considering polytrauma research, the extent of the simultaneously applied single traumata can be investigated more closely with regard to the whole animal.

In summary, when considering both the advantages and disadvantages of using rat models for trauma research, in planning and performing animal experiments the criteria of the Reduction, Replacement, Refinement (3 R's), which were published by Russell and Burch in 1959 in 'The Principles of Humane Experimental Technique', should additionally always be considered [205]. Animal welfare should always be the first priority together with the reduction of animal pain and suffering. When planning animal experiments, first all potential replacement and alternative reliable experimental methods should be excluded. When there is no alternative, many basic trauma and regeneration processes have been shown to be similar to humans, and thus make the rat a suitable model for translational research.

\section{Abbreviations}

AIS: abbreviated injury scale; ATC: acute traumatic coagulopathy; ATLS: Advanced Trauma Life Support; APTEM: activation as EXTEM with aprotinin to inhibit fibrinolysis; aPTT: activated partial thromboplastin time; BAL: bronchoalveolar lavage fluid; CCl: controlled cortical impact; cNOS: constitutive nitric oxide synthase; CNS: central nervous system; CSF: cerebrospinal fluid; CT: clotting time; DAMPS: damage-associated molecular patterns; DC: dendritic cells; F: factor; FACS: fluorescence-activated cell sorting; Gb: gigabases; GFAP: glial fibrillary acidic protein; GH: growth hormone; HES: hydroxyethyl starch; HFABP: heart fatty acid binding protein; HR: heart rate; HS: hemorrhagic shock; IEGs: immediate early genes; IL-1 $\beta$ : interleukin-1 beta; IL-6: interleukin-6; IL-18: interleukin-18; ISS: injury severity score; LFP: lateral fluid percussion injury; LPS: lipopolysaccharide; MAP: mean arterial pressure; MCF: maximum clot firmness; NO: nitric oxide; NOS: nitric oxide synthase; iNOS: inducible nitric oxide synthase; PIM: pulmonary intravascular macrophage; PT: prothrombin time; 3 R's: Reduction, Replacement, Refinement; ROTEM: rotation thromboelastometry; TBI: traumatic brain injury; TEM: thromboelastometry; TIC: traumainduced coagulopathy; TIMP: tissue inhibitor of metalloproteinase; TNF: tumor necrosis factor; TLR: toll-like receptor; TT: thrombin time; WHO: World Health Organization.

\section{Acknowledgements}

This work was conducted in the framework of the CRC 1149 funded by the Deutsche Forschungsgemeinschaft (DFG, German Research Foundation)— Project number 251293561. This work is also supported by an UIm UniversityBundeswehr Krankenhaus UIm research initiative.

\section{Authors' contributions}

$B W, I L, M H L, A P, B K, B R$, HS and MK drafted the work. BW, IL, MHL, AP, JP, KSK, BK, BR. HS and MK substantially revised the work. All authors read and approved the final manuscript.

\section{Funding}

This work was conducted in the framework of the CRC1149 funded by the Deutsche Forschungsgemeinschaft (DFG, German Research Foundation)Project number 251293561. This work is also supported by an UIm UniversityBundeswehr Krankenhaus UIm research initiative.

\section{Availability of data and materials}

Not applicable.

Ethics approval and consent to participate

Not applicable.

Consent for publication

Not applicable.

Competing interests

The authors declare that they have no competing interests.

\section{Author details}

${ }^{1}$ Department of Traumatology, Hand-, Plastic-, and Reconstructive Surgery, Center of Surgery, University of UIm Medical School, Albert-Einstein-Allee 23, 89081 Ulm, Germany. ${ }^{2}$ Institute of Orthopedic Research and Biomechanics, University Medical Center Ulm, Ulm, Germany. ${ }^{3}$ Institute of Clinical and Experimental Trauma-Immunology, University of UIm, Ulm, Germany. ${ }^{4}$ Institute of Dermatology and Allergology, University Medical Center, University of Ulm, Ulm, Germany. ${ }^{5}$ Institute of Physiological Chemistry, University of Ulm, Ulm, Germany. ${ }^{6}$ Institute of Transfusion Medicine, University of Ulm and Institute of Clinical Transfusion Medicine and Immunogenetics UIm, German Red Cross Blood Transfusion Service Baden-Württemberg - Hessen and University Hospital UIm, UIm, Germany. ${ }^{7}$ Department of Trauma, Hand and Reconstructive Surgery, Goethe University Frankfurt, Frankfurt, Germany. ${ }^{8}$ Department of Radiology and Nuclear Medicine, Experimental Radiology, Otto-von-Guericke University, Magdeburg, Germany.

Received: 27 February 2019 Accepted: 29 August 2019

Published online: 05 September 2019

\section{References}

1. Krug EG, Sharma GK, Lozano R. The global burden of injuries. Am J Public Health. 2000;90(4):523-6.

2. Murray CJ, Atkinson C, Bhalla K, Birbeck G, Burstein R, Chou D, et al. The state of US health, 1990-2010: burden of diseases, injuries, and risk factors. JAMA. 2013;310(6):591-608.

3. Pape HC, Lefering R, Butcher N, Peitzman A, Leenen L, Marzi I, et al. The definition of polytrauma revisited: an international consensus process 
and proposal of the new 'Berlin definition'. J Trauma Acute Care Surg. 2014;77(5):780-6.

4. Lecky FE, Bouamra O, Woodford M, Alexandrescu R, O'Brien SJ. Epidemiology of Polytrauma. In: Pape H-C, Peitzman AB, William Schwab C, Giannoudis PV, editors. Damage control management in the polytrauma patient. New York: Springer; 2010. p. 13-24.

5. Evans JA, van Wessem KJP, McDougall D, Lee KA, Lyons T, Balogh ZJ. Epidemiology of traumatic deaths: comprehensive population-based assessment. World J Surg. 2010;34(1):158-63.

6. Gebhard F, Huber-Lang M. Polytrauma - pathophysiology and management principles. Langenbeck Arch Surg. 2008;393(6):825-31.

7. Hecke F, Schmidt U, Kola A, Bautsch W, Klos A, Kohl J. Circulating complement proteins in multiple trauma patients—correlation with injury severity, development of sepsis, and outcome. Crit Care Med. 1997;25(12):2015-24.

8. Leung $\mathrm{CH}$, Caldarone CA, Wang F, Venkateswaran S, Ailenberg M, Vadasz $B$, et al. Remote ischemic conditioning prevents lung and liver injury after hemorrhagic shock/resuscitation potential role of a humoral plasma factor. Ann Surg. 2015;261(6):1215-25.

9. Macko AR, Moore H, Cap AP, Meledeo MA, Moore EE, Sheppard FR. Tissue injury suppresses fibrinolysis following hemorrhagic shock in non-human primates (rhesus macaque). J Trauma Acute Care Surg. 2017. https://doi.org/10.1097/TA.0000000000001379.

10. Carbone L, Austin J. Pain and laboratory animals: publication practices for better data reproducibility and better animal welfare. PLoS ONE. 2016;11(5):e0155001.

11. Clemensen J, Rasmussen LV, Abelson KSP. Transdermal fentanyl solution provides long-term analgesia in the hind-paw incisional model of postoperative pain in male rats. In vivo (Athens, Greece). 2018;32(4):713-9.

12. Griffin MJ, Letson HL, Dobson GP. Buprenorphine analgesia leads to coagulopathy and increased plasma fibrinogen in healthy rats: implications for small animal research. Shock. 2017:48(1):78-84.

13. Morgan CE, Prakash VS, Vercammen JM, Pritts T, Kibbe MR. Development and validation of 4 different rat models of uncontrolled hemorrhage. JAMA Surg. 2015;150(4):316-24.

14. Wang ND, Stevens MH, Doty DB, Hammond EH. Blunt chest trauma: an experimental model for heart and lung contusion. J Trauma Injury Infect Crit Care. 2003;54(4):744-8.

15. Pritchard JJ. Repair of fractures of the parietal bone in rats. J Anat. 1946;80(2):55.

16. Abdullahi A, Amini-Nik S, Jeschke MG. Animal models in burn research. Cell Mol Life Sci CMLS. 2014;71(17):3241-55.

17. Dorsett-Martin WA. Rat models of skin wound healing: a review. Wound Rep Reg. 2004;12:591-9.

18. Dixon CE, Lyeth BG, Povlishock JT, Findling RL, Hamm RJ, Marmarou A, et al. A fluid percussion model of experimental brain injury in the rat. J Neurosurg. 1987;67(1):110-9.

19. Akscyn RM, Franklin JL, Gavrikova TA, Schwacha MG, Messina JL. A rat model of concurrent combined injuries (polytrauma). Int J Clin Exp Med. 2015;8(11):20097-110.

20. Koolhaas JM. The laboratory rat. In: Hubrecht R, Kirkwood J, editors. The UFAW handbook on the care and management of laboratory and other research animals. 8th ed. Chichester: John Wiley \& Sons; 2010. p. 311-26.

21. Iannaccone P, Jacob HJ. Rats! Dis Model Mech. 2009;2(5-6):206-10.

22. Baker H. The laboratory rat: volume I-biology and diseases. Cambridge: Academic Press; 1979.

23. Krinke GJ, editor. The laboratory rat. San Diego: Academic; 2000. ISBN: 9780080533469 .

24. Greenhouse DD, Festing MFW, Hasan S, Cohen AL. Catalogue of inbred strains of rats. In: Hedrich HJ, editor. Genetic monitoring of inbred strains of rats. Stuttgart: Gustav Fischer; 1990. p. 410-480.

25. Gibbs RA, Weinstock GM, Metzker ML, Muzny DM, Sodergren EJ, Scherer S, et al. Genome sequence of the Brown Norway rat yields insights into mammalian evolution. Nature. 2004;428(6982):493-521.

26. Tesson L, Cozzi J, Menoret S, Remy S, Usal C, Fraichard A, et al. Transgenic modifications of the rat genome. Transgenic Res. 2005; 14(5):531-46.

27. Tompkins RG. Genomics of injury: the Glue Grant experience. J Trauma Acute Care. 2015;78(4):671-86.
28. Weckbach S, Perl M, Heiland T, Braumuller S, Stahel PF, Flierl MA, et al. A new experimental polytrauma model in rats: molecular characterization of the early inflammatory response. Mediators Inflamm 2012;2012:890816.

29. Lim GB. Milestone 2: warfarin: from rat poison to clinical use. Nat Rev Cardiol. 2017. https://doi.org/10.1038/nrcardio.2017.172.

30. Tomiuga T, Kobayashi M, Nakajima Y, Bessho M, Katoh Y, Hara K, et al. Effects of menatetrenone on the decrease in calcium balance induced by vitamin K-deficient diet and sodium loading in rats. Jpn J Pharmacol. 1994;65(1):35-43.

31. Sauaia A, Moore FA, Moore EE, Moser KS, Brennan R, Read RA, et al. Epidemiology of trauma deaths: a reassessment. J Trauma. 1995;38(2):185-93.

32. Brohi K, Singh J, Heron M, Coats T. Acute traumatic coagulopathy. J Trauma. 2003;54(6):1127-30.

33. Theusinger OM, Baulig W, Seifert B, Muller SM, Mariotti S, Spahn DR Changes in coagulation in standard laboratory tests and ROTEM in trauma patients between on-scene and arrival in the emergency department. Anesth Analg. 2015;120(3):627-35.

34. Engels PT, Rezende-Neto JB, Al Mahroos M, Scarpelini S, Rizoli SB, Tien HC. The natural history of trauma-related coagulopathy: implications for treatment. J Trauma. 2011;71(5 Suppl 1):S448-55.

35. Frith D, Goslings JC, Gaarder C, Maegele M, Cohen MJ, Allard S, et al. Definition and drivers of acute traumatic coagulopathy: clinical and experimental investigations. J Thromb Haemost JTH. 2010;8(9):1919-25.

36. Gangloff C, Grimault O, Theron M, Pichavant K, Galinat H, Mingant F, et al. A clinically relevant and bias-controlled murine model to study acute traumatic coagulopathy. Sci Rep. 2018;8(1):5783.

37. Wisbach G, Tobias S, Woodman R, Spalding A, Lockette W. Preserving cardiac output with beta-adrenergic receptor blockade and inhibiting the Bezold-Jarisch reflex during resuscitation from hemorrhage. J Trauma. 2007;63(1):26-32.

38. Ikuma H, Wada H, Mori Y, Shimura M, Hiyoyama K, Nakasaki T, et al. Hemostatic markers in Japanese patients undergoing anticoagulant therapy under thrombo-test monitoring. Blood Coagul Fibrinolysis. 1999;10(7):429-34.

39. Karges $\mathrm{HE}$, Funk KA, Ronneberger $\mathrm{H}$. Activity of coagulation and fibrinolysis parameters in animals. Arzneimittelforschung. 1994;44(6):793-7.

40. Wolfensohn SA, Maggie L. Handbook of laboratory animal-management and welfare. 3rd ed. Chichester: Blackwell publishing; 2003.

41. Hayakawa MGS, leko M, Honma Y, Homma T, Yanagida Y. Massive amounts of tissue factor induce fibrinogenolysis without tissue hypoperfusion in rats. Shock. 2013;39(6):514-9.

42. Daly ME. Determinants of platelet count in humans. Haematologica. 2011:96(1):10-3.

43. Siller-Matula JM, Plasenzotti R, Spiel A, Quehenberger P, Jilma B. Interspecies differences in coagulation profile. Thromb Haemost. 2008:100(3):397-404.

44. Derian CK, Santulli RJ, Tomko KA, Haertlein BJ, Andrade-Gordon P. Species differences in platelet responses to thrombin and SFLLRN. receptor-mediated calcium mobilization and aggregation, and regulation by protein kinases. Thromb Res. 1995;78(6):505-19.

45. Letson HL, Dobson GP. Differential contributions of platelets and fibrinogen to early coagulopathy in a rat model of hemorrhagic shock. Thromb Res. 2016;141:58-65.

46. Stansbury LG, Hess AS, Thompson K, Kramer B, Scalea TM, Hess JR. The clinical significance of platelet counts in the first 24 hours after severe injury. Transfusion. 2013;53(4):783-9.

47. Rourke C, Curry N, Khan S, Taylor R, Raza I, Davenport R, et al. Fibrinogen levels during trauma hemorrhage, response to replacement therapy, and association with patient outcomes. J Thromb Haemost JTH. 2012;10(7):1342-51

48. Lemini C, Jaimez R, Franco Y. Gender and inter-species influence on coagulation tests of rats and mice. Thromb Res. 2007;120(3):415-9.

49. Kudriashova O, Zateishchikov DA, Barinov VG, Privalov DV, Tsimbalova $T E$, Zateishchikova AA, et al. Gender differences in the state of the system of hemostasis in patients with ischemic heart disease. Kardiologiia. 2002;42(5):29-33.

50. Matsuura M, Satoh S, Kobayashi F, Uchida K, Matsubara T. Vitamin K-reversible hypoprothrombinemia in rats: comparison of 
hypoprothrombinemic changes in various strains of rats caused by vitamin $\mathrm{K}$ deficiency and antibiotic treatment. J Toxicol Sci. 1989;14(3):165-80.

51. Torres Filho I. Hemorrhagic shock and the microvasculature. Compr Physiol. 2017;8(1):61-101.

52. Keitel J, Hussmann B, Lendemans S, de Groot H, Rohrig R. Comparison of malated Ringer's with two other balanced crystalloid solutions in resuscitation of both severe and moderate hemorrhagic shock in rats. Biomed Res Int. 2015:2015:151503.

53. Frink $M$, Andruszkow $H$, Zeckey $C$, Krettek C, Hildebrand F. Experimental trauma models: an update. J Biomed Biotechnol. 2011;2011:797383.

54. Guly HR, Bouamra O, Spiers M, Dark P, Coats T, Lecky FE, et al. Vital signs and estimated blood loss in patients with major trauma: testing the validity of the ATLS classification of hypovolaemic shock. Resuscitation. 2011;82(5):556-9.

55. Choi JY, Lee WH, Yoo TK, Park I, Kim DW. A new severity predicting index for hemorrhagic shock using lactate concentration and peripheral perfusion in a rat model. Shock. 2012;38(6):635-41.

56. Letson HL, Dobson GP. Unexpected $100 \%$ survival following $60 \%$ blood loss using small-volume $7.5 \% \mathrm{Nacl}$ with adenocaine and $\mathrm{Mg}(2+)$ in the rat model of extreme hemorrhagic shock. Shock. 2011;36(6):586-94.

57. Reynolds PS, Song KS, Tamariz FJ, Barbee RW. Hypertension and vulnerability to hemorrhagic shock in a rat model. Shock. 2015;43(2):148-56.

58. Reisz JA, Wither MJ, Moore EE, Slaughter AL, Moore HB, Ghasabyan A, et al. All animals are equal but some animals are more equal than others: plasma lactate and succinate in hemorrhagic shock-A comparison in rodents, swine, nonhuman primates, and injured patients. J Trauma Acute Care Surg. 2018;84(3):537-41.

59. Rose R, Kheirabadi BS, Klemcke HG. Arterial blood gases, electrolytes, and metabolic indices associated with hemorrhagic shock: inter- and intrainbred rat strain variation. J Appl Physiol (Bethesda, Md : 1985). 2013;114(9):1165-73.

60. Klemcke HG, Joe B, Calderon ML, Rose R, Oh T, Aden J, et al. Genetic influences on survival time after severe hemorrhage in inbred rat strains. Physiol Genomics. 2011;43(12):758-65.

61. Klemcke HG, Baer DG, Pankratz VS, Cox A, Cortez DS, Garrett MR, et al. Is survival time after hemorrhage a heritable, quantitative trait?: an initial assessment. Shock. 2008:29(6):748-53.

62. Troy BP, Hopkins DA, Keay KA. The hemodynamic response to blood loss in the conscious rat: contributions of cardiac vagal and cardiac spinal signals. Shock. 2014;41(4):282-91.

63. Balaszczuk AM, Arreche ND, McLaughlin M, Arranz C, Fellet AL. Nitric oxide synthases are involved in the modulation of cardiovascular adaptation in hemorrhaged rats. Vasc Pharmacol. 2006;44(6):417-26.

64. Mok YYP, Atan MSBM, Ping CY, Jing WZ, Bhatia M, Moochhala S, et al. Role of hydrogen sulphide in haemorrhagic shock in the rat: protective effect of inhibitors of hydrogen sulphide biosynthesis. Br J Pharmacol. 2004;143(7):881-9.

65. Koziol JM, Rush BF Jr, Smith SM, Machiedo GW. Occurrence of bacteremia during and after hemorrhagic shock. J Trauma. 1988;28(1):10-6.

66. Rush BF Jr, Redan JA, Flanagan JJ Jr, Heneghan JB, Hsieh J, Murphy TF, et al. Does the bacteremia observed in hemorrhagic shock have clinical significance? A study in germ-free animals. Ann Surg. 1989;210(3):342-5 (discussion 6-7).

67. Adolphs J, Schmidt DK, Mousa SA, Kamin B, Korsukewitz I, Habazettl $\mathrm{H}$, et al. Thoracic epidural anesthesia attenuates hemorrhageinduced impairment of intestinal perfusion in rats. Anesthesiology. 2003;99(3):685-92.

68. Ba ZF, Shimizu T, Szalay L, Bland KI, Chaudry IH. Gender differences in small intestinal perfusion following trauma hemorrhage: the role of endothelin-1. Am J Physiol Gastrointest Liver Physiol. 2005;288(5):G860-5.

69. Li T, Xiao X, Zhang J, Zhu Y, Hu Y, Zang J, et al. Age and sex differences in vascular responsiveness in healthy and trauma patients: contribution of estrogen receptor-mediated Rho kinase and PKC pathways. Am J Physiol Heart Circ Physiol. 2014;306(8):H1 105-15.

70. Liu LM, Dubick MA. Hemorrhagic shock-induced vascular hyporeactivity in the rat: relationship to gene expression of nitric oxide synthase, endothelin-1, and select cytokines in corresponding organs. J Surg Res. 2005;125(2):128-36.
71. Rhee CJ, Kibler KK, Easley RB, Andropoulos DB, Czosnyka M, Smielewski $P$, et al. Renovascular reactivity measured by near-infrared spectroscopy. J Appl Physiol (Bethesda, Md: 1985). 2012;113(2):307-14.

72. Hunt PA, Greaves I, Owens WA. Emergency thoracotomy in thoracic trauma—a review. Injury Int J Care Injured. 2006;37(1):1-19.

73. Raghavendran K, Davidson BA, Woytash JA, Helinski JD, Marschke CJ, Manderscheid PA, et al. The evolution of isolated bilateral lung contusion from blunt chest trauma in rats: cellular and cytokine responses. Shock. 2005:24(2):132-8.

74. Liener UC, Knoferl MW, Strater J, Barth TFE, Pauser EM, Nussler AK, et al. Induction of apoptosis following blunt chest trauma. Shock. 2003:20(6):511-6.

75. Wagner N, Franz N, Dieteren S, Perl M, Mors K, Marzi I, et al. Acute alcohol binge deteriorates metabolic and respiratory compensation capability after blunt chest trauma followed by hemorrhagic shock-a new research model. Alcohol Clin Exp Res. 2017:41(9):1559-67.

76. Relja B, Wagner N, Franz N, Dieteren S, Mors K, Schmidt J, et al. Ethyl pyruvate reduces acute lung damage following trauma and hemorrhagic shock via inhibition of NF-kappaB and HMGB1. Immunobiology. 2018:223(3):310-8.

77. Raghavendran K, Davidson BA, Helinski JD, Marschket CJ, Manderscheid P, Woytash $\mathrm{JA}$, et al. A rat model for isolated bilateral lung contusion from blunt chest trauma. Anesth Analg. 2005;101(5):1482-9.

78. Kalbitz M, Amann EM, Bosch B, Palmer A, Schultze A, Pressmar J, et al. Experimental blunt chest trauma-induced myocardial inflammation and alteration of gap-junction protein connexin 43. PLoS ONE. 2017;12(11):e0187270.

79. Cohn SM. Pulmonary contusion: review of the clinical entity. J Trauma Injury Infect Crit Care. 1997:42(5):973-9.

80. Johnson JA, Cogbill TH, Winga ER. Determinants of outcome after pulmonary contusion. J Trauma Injury Infect Crit Care. 1986;26(8):695-7.

81. Clemedson CJ, Pettersson H. Genesis of respiratory and circulatory changes in blast injury. Am J Physiol. 1953;174(2):316-20.

82. Liener UC, Perl M, Huber-Lang MS, Seitz DH, Bruckner UB, Gebhard F, et al. Is the function of alveolar macrophages altered following blunt chest trauma? Langenbecks Arch Surg. 2011;396(2):251-9.

83. Jonker MA, Hermsen JL, Gomez FE, Sano Y, Kudsk KA. Injury induces localized airway increases in pro-inflammatory cytokines in humans and mice. Surg Infect. 2011;12(1):49-56.

84. Niesler U, Palmer A, Radermacher P, Huber-Lang MS. Role of alveolar macrophages in the inflammatory response after trauma. Shock. 2014;42(1):3-10.

85. Vaure C, Liu YQ. A comparative review of toll-like receptor 4 expression and functionality in different animal species. Frontiers in Immunology. 2014;5.

86. Smirnova I, Poltorak A, Chan EKL, McBride C, Beutler B. Phylogenetic variation and polymorphism at the Toll-like receptor 4 locus (TLR4). Genome Biol. 2000. https://doi.org/10.1186/gb-2000-1-1-research002.

87. Droemann D, Goldmann T, Branscheid D, Clark R, Dalhoff K, Zabel $P$, et al. Toll-like receptor 2 is expressed by alveolar epithelial cells type II and macrophages in the human lung. Histochem Cell Biol. 2003;119(2):103-8.

88. Schneberger D, Aharonson-Raz K, Singh B. Pulmonary intravascular macrophagesand lung health: what are we missing? Am J Physiol Lung Cell Mol Physiol. 2012;302(6):L498-503.

89. Warner AE, Brain JD. The cell biology and pathogenic role of pulmonary intravascular macrophages. Am J Physiol. 1990;258(2 Pt 1):L1-12.

90. Thenappan T, Goel A, Marsboom G, Fang YH, Toth PT, Zhang HJ, et al. A central role for $\mathrm{CD} 68(+)$ macrophages in hepatopulmonary syndrome. Reversal by macrophage depletion. Am J Respir Crit Care Med. 2011;183(8):1080-91.

91. Tahedl D, Wirkes A, Tschanz SA, Ochs M, Mühlfeld C. How common is the lipid body-containing interstitial cell in the mammalian lung. Am J Physiol Lung Cell Mol Physiol. 2014;307(5):L386-94.

92. Kobzik L, Bredt DS, Lowenstein CJ, Drazen J, Gaston B, Sugarbaker $D$, et al. Nitric oxide synthase in human and rat lung: immunocytochemical and histochemical localization. Am J Respir Cell Mol Biol. 1993;9(4):371-7.

93. Padgett EL, Pruett SB. Rat, mouse and human neutrophils stimulated by a variety of activating agents produce much less nitrite than rodent macrophages. Immunology. 1995;84(1):135-41. 
94. Hofmann W, Koblinger L, Martonen TB. Structural differences between human and rat lungs -implications for monte-carlo modeling of aerosol deposition. Health Phys. 1989;57:41-7.

95. Dogan H, Sarikaya S, Neijmann ST, Uysal E, Yucel N, Ozucelik DN, et al. $\mathrm{N}$-terminal pro-B-type natriuretic peptide as a marker of blunt cardiac contusion in trauma. Int J Clin Exp Pathol. 2015;8(6):6786-92.

96. Herman E, Knapton A, Rosen E, Zhang J, Estis J, Agee SJ, et al. Baseline serum cardiac troponin I concentrations in Sprague-Dawley, spontaneous hypertensive, Wistar, Wistar-Kyoto, and Fisher rats as determined with an ultrasensitive immunoassay. Toxicol Pathol. 2011;39(4):653-63.

97. Bonnarens F, Einhorn TA. Production of a standard closed fracture in laboratory animal bone. J Orthop Res. 1984;2(1):97-101.

98. An YH, Friedman RJ, Parent T, Draughn RA. Production of a standard closed fracture in the rat tibia. J Orthop Trauma. 1994;8(2):111-5.

99. Histing T, Garcia P, Holstein JH, Klein M, Matthys R, Nuetzi R, et al. Small animal bone healing models: standards, tips, and pitfalls results of a consensus meeting. Bone. 2011;49(4):591-9.

100. Shao Y, Guan Y, Wang L, Qiu Z, Liu M, Chen Y, et al. CRISPR/Cas-mediated genome editing in the rat via direct injection of one-cell embryos. Nat Protoc. 2014;9(10):2493-512.

101. Takeuchi T, Suzuki H, Sakurai S, Nogami H, Okuma S, Ishikawa H. Molecular mechanism of growth hormone $(\mathrm{GH})$ deficiency in the spontaneous dwarf rat: detection of abnormal splicing of GH messenger ribonucleic acid by the polymerase chain reaction. Endocrinology. 1990;126(1):31-8.

102. Tsuchida A, Yokoi N, Namae M, Fuse M, Masuyama T, Sasaki M, et al. Phenotypic characterization of the Komeda miniature rat Ishikawa, an animal model of dwarfism caused by a mutation in Prkg2. Comp Med. 2008;58(6):560-7.

103. McCann RM, Colleary G, Geddis C, Clarke SA, Jordan GR, Dickson GR, et al. Effect of osteoporosis on bone mineral density and fracture repair in a rat femoral fracture model. J Orthop Res. 2008;26(3):384-93.

104. Stuermer EK, Sehmisch S, Rack T, Wenda E, Seidlova-Wuttke D, Tezval M, et al. Estrogen and raloxifene improve metaphyseal fracture healing in the early phase of osteoporosis. A new fracture-healing model at the tibia in rat. Langenbecks Arch Surg. 2010;395(2):163-72.

105. Nunamaker DM. Experimental models of fracture repair. Clin Orthop Relat Res. 1998;355(Suppl):S56-65.

106. Sun $\mathrm{Q}$, Turner $\mathrm{CH}$. Two inbred rat strains that differ substantially in hip fragility. Calcif Tissue Int. 2003;72(4):498-504.

107. Strube P, Mehta M, Baerenwaldt A, Trippens J, Wilson CJ, Ode A, et al. Sex-specific compromised bone healing in female rats might be associated with a decrease in mesenchymal stem cell quantity. Bone. 2009;45(6):1065-72.

108. Zheng HJ, Martin JA, Duwayri Y, Falcon G, Buckwalter JA. Impact of aging on rat bone marrow-derived stem cell chondrogenesis. J Gerontol A Biol. 2007:62(2):136-48.

109. Kilborn SH, Trudel G, Uhthoff H. Review of growth plate closure compared with age at sexual maturity and lifespan in laboratory animals. Contemp Top Lab Anim. 2002;41(5):21-6.

110. Lu CY, Miclau T, Hu D, Hansen E, Tsui K, Puttlitz C, et al. Cellular basis for age-related changes in fracture repair. J Orthop Res. 2005;23(6):1300-7.

111. Lu CY, Hansen E, Sapozhnikova A, Hu D, Miclau T, Marcucio RS Effect of age on vascularization during fracture repair. J Orthop Res. 2008;26(10):1384-9.

112. Einhorn TA. The science of fracture healing. J Orthop Trauma. 2005;19(10):S4-6.

113. Augat P, Simon U, Liedert A, Claes L. Mechanics and mechano-biology of fracture healing in normal and osteoporotic bone. Osteoporos Int. 2005;16(Suppl 2):S36-43.

114. Dorsett-Martin WA. Rat models of skin wound healing: a review. Wound Repair Regen. 2004;12(6):591-9.

115. Wong WW, Sorkin M, Glotzbach JP, Longaker MT, Gurtner GC. Surgical approaches to create murine models of human wound healing. J Biomed Biotechnol. 2011;2011:969618.

116. Michielsen CP, Bloksma N, Ultee A, van Mil F, Vos JG. Hexachlorobenzene-induced immunomodulation and skin and lung lesions: a comparison between brown Norway, Lewis, and Wistar rats. Toxicol Appl Pharmacol. 1997;144(1):12-26.

117. Ludwik K, Branski AAM, Haidy R, Jeschke MG, Sanford AP, Herndon DN Emerging infections in burns. Surg Infect. 2009;10:389-97.
118. Kulp GA, Tilton RG, Herndon DN, Jeschke MG. Hyperglycemia exacerbates burn-induced liver inflammation via noncanonical nuclear factor-kappaB pathway activation. Mol Med (Cambridge, Mass). 2012;18:948-56.

119. Fang $H$, Jin $H$, Hua $C$, Liu $A$, Song $Z$, Chen $X$, et al. The LPS responsiveness in $\mathrm{BN}$ and lew rats and its severity are modulated by the liver. J Immunol Res. 2018;2018:6328713.

120. Gurfinkel R, Singer AJ, Cagnano E, Rosenberg L. Development of a novel animal burn model using radiant heat in rats and swine. Acad Emerg Med. 2010;17(5):514-20.

121. Almeida-Suhett CP, Li Z, Marini AM, Braga MF, Eiden LE. Temporal course of changes in gene expression suggests a cytokine-related mechanism for long-term hippocampal alteration after controlled cortical impact. J Neurotrauma. 2014;31(7):683-90.

122. Dixon CE, Lighthall JW, Anderson TE. Physiologic, histopathologic, and cineradiographic characterization of a new fluid-percussion model of experimental brain injury in the rat. J Neurotrauma. 1988;5(2):91-104.

123. Cernak I. Animal models of head trauma. NeuroRx. 2005:2(3):410-22.

124. Hu Y, Wu Y, Tian K, Lan D, Chen X, Xue M, et al. Identification of ideal resuscitation pressure with concurrent traumatic brain injury in a rat model of hemorrhagic shock. J Surg Res. 2015;195(1):284-93.

125. Albert-Weissenberger C, Siren AL. Experimental traumatic brain injury. Exp Transl Stroke Med. 2010;2(1):16.

126. Rakos G, Kis Z, Nagy D, Lur G, Farkas T, Hortobagyi T, et al. Evans Blue fluorescence permits the rapid visualization of non-intact cells in the perilesional rim of cold-injured rat brain. Acta Neurobiol Exp. 2007:67(2):149-54.

127. Eriskat J, Furst M, Stoffel M, Baethmann A. Correlation of lesion volume and brain swelling from a focal brain trauma. Acta Neurochir Suppl. 2003;86:265-6.

128. Gaetz M. The neurophysiology of brain injury. Clin Neurophysiol. 2004;115:4-18.

129. Richmond DR, Damon EG, Bowen IG, Fletcher ER, White CS. Air-blast studies with eight species of mammals. In: Technical progress report DASA 1854. Fission Prod Inhal Proj; 1967. p. 1-44.

130. Reid WM, Rolfe A, Register D, Levasseur JE, Churn SB, Sun D. Strainrelated differences after experimental traumatic brain injury in rats. J Neurotrauma. 2010;27(7):1243-53.

131. Shultz SR, MacFabe DF, Foley KA, Taylor R, Cain DP. A single mild fluid percussion injury induces short-term behavioral and neuropathological changes in the Long-Evans rat: support for an animal model of concussion. Behav Brain Res. 2011;224(2):326-35.

132. Povlishock JT, Hayes RL, Michel ME, Mclntosh TK. Workshop on animal models of traumatic brain injury. J Neurotrauma. 1994;11(6):723-32.

133. Cordeiro MF, Horn AP. Stem cell therapy in intracerebral hemorrhage rat model. World J Stem Cells. 2015;7(3):618-29.

134. Bolouri H, Saljo A, Viano DC, Hamberger A. Animal model for sportrelated concussion; ICP and cognitive function. Acta Neurol Scand. 2012;125(4):241-7.

135. Eakin K, Baratz-Goldstein R, Pick CG, Zindel O, Balaban CD, Hoffer ME, et al. Efficacy of $\mathrm{N}$-acetyl cysteine in traumatic brain injury. PLoS ONE. 2014;9(4):e90617.

136. Mychasiuk R, Hehar H, Farran A, Esser MJ. Mean girls: sex differences in the effects of mild traumatic brain injury on the social dynamics of juvenile rat play behaviour. Behav Brain Res. 2014;259:284-91.

137. Simon DW, McGeachy MJ, Bayir H, Clark RSB, Loane DJ, Kochanek PM. The far-reaching scope of neuroinflammation after traumatic brain injury. Nat Rev Neurol. 2017;13(9):572.

138. Kelley BJ, Lifshitz J, Povlishock JT. Neuroinflammatory responses after experimental diffuse traumatic brain injury. J Neuropathol Exp Neurol. 2007;66(11):989-1001.

139. Fidan $\mathrm{E}$, Lewis J, Kline $\mathrm{AE}$, Garman $\mathrm{RH}$, Alexander $\mathrm{H}$, Cheng JP, et al. Repetitive mild traumatic brain injury in the developing brain: effects on long-term functional outcome and neuropathology. J Neurotrauma. 2016;33(7):641-51.

140. Chiu CC, Liao YE, Yang LY, Wang JY, Tweedie D, Karnati HK, et al. Neuroinflammation in animal models of traumatic brain injury. J Neurosci Methods. 2016:272:38-49.

141. Ramlackhansingh AF, Brooks DJ, Greenwood RJ, Bose SK, Turkheimer FE, Kinnunen KM, et al. Inflammation after trauma: microglial activation and traumatic brain injury. Ann Neurol. 2011;70(3):374-83. 
142. Johnson VE, Stewart JE, Begbie FD, Trojanowski JQ, Smith DH, Stewart W. Inflammation and white matter degeneration persist for years after a single traumatic brain injury. Brain. 2013;136(Pt 1):28-42.

143. Liu HD, Li W, Chen ZR, Hu YC, Zhang DD, Shen W, et al. Expression of the NLRP3 inflammasome in cerebral cortex after traumatic brain injury in a rat model. Neurochem Res. 2013;38(10):2072-83.

144. Yatsiv I, Morganti-Kossmann MC, Perez D, Dinarello CA, Novick D, Rubinstein $\mathrm{M}$, et al. Elevated intracranial IL-18 in humans and mice after traumatic brain injury and evidence of neuroprotective effects of IL-18-binding protein after experimental closed head injury. J Cereb Blood Flow Metab. 2002;22(8):971-8.

145. Lorente L, Martin MM, Sole-Violan J, Blanquer J, Labarta L, Diaz C, et al. Association of sepsis-related mortality with early increase of TIMP-1/MMP-9 ratio. PLoS ONE. 2014;9(4):e94318.

146. Kawata K, Liu CY, Merkel SF, Ramirez SH, Tierney RT, Langford D. Blood biomarkers for brain injury: what are we measuring? Neurosci Biobehav Rev. 2016;68:460-73.

147. Shultz SR, McDonald SJ, Vonder Haar C, Meconi A, Vink R, van Donkelaar $\mathrm{P}$, et al. The potential for animal models to provide insight into mild traumatic brain injury: translational challenges and strategies. Neurosci Biobehav Rev. 2017;76(Pt B):396-414.

148. Pitkanen A, Immonen R, Ndode-Ekane X, Grohn O, Stohr T, Nissinen J. Effect of lacosamide on structural damage and functional recovery after traumatic brain injury in rats. Epilepsy Res. 2014;108(4):653-65.

149. Pitkanen A, Mclntosh TK. Animal models of post-traumatic epilepsy. J Neurotrauma. 2006;23(2):241-61.

150. Pitkanen A, Kyyriäinen J, Andrade P, Pasanen L, Ndode-Ekane XE. Epilepsy after traumatic brain injury. Models Seizures Epilepsy. 2017;2:661-81.

151. Wang Y, Hameed MQ, Rakhade SN, Iglesias AH, Muller PA, Mou DL, et al. Hippocampal immediate early gene transcription in the rat fluid percussion traumatic brain injury model. NeuroReport. 2014;25(12):954-9.

152. Awasthi D, Kutz SC, Beuerman R, Nguyen D, Carey ME, Zeiller S. Early gene expression in the rat cortex after experimental traumatic brain injury and hypotension. Neurosci Lett. 2003;345(1):29-32.

153. Hayes RL, Yang K, Raghupathi R, Mclntosh TK. Changes in gene expression following traumatic brain injury in the rat. J Neurotrauma. 1995;12(5):779-90.

154. Dutcher SA, Underwood BD, Walker PD, Diaz FG, Michael DB. Patterns of immediate early gene mRNA expression following rodent and human traumatic brain injury. Neurol Res. 1999;21(3):234-42.

155. Whitfield PC, Pickard JD. Expression of the immediate early genes C-Fos and c-Jun after head injury in man. Neurol Res. 2000;22(2):138-44.

156. Michael DB, Byers DM, Irwin LN. Gene expression following traumatic brain injury in humans: analysis by microarray. J Clin Neurosci. 2005;12(3):284-90.

157. Paffrath T, Lefering R, Flohe S. How to define severely injured patients? - an Injury Severity Score (ISS) based approach alone is not sufficient. Injury. 2014;45(Suppl 3):S64-9.

158. Trupka A, Kierse R, Waydhas C, Nast-Kolb D, Blahs U, Schweiberer L, et al. Shock room diagnosis in polytrauma. Value of thoracic CT. Der Unfallchirurg. 1997;100(6):469-76.

159. Sobrino J, Shafi S. Timing and causes of death after injuries. Proceedings (Baylor University Medical Center). 2013;26(2):120-3.

160. Huber-Lang M, Lambris JD, Ward PA. Innate immune responses to trauma. Nat Immunol. 2018;19(4):327-41.

161. Relja B, Mors K, Marzi I. Danger signals in trauma. Eur J Trauma Emerg Surg. 2018;44(3):301-16.

162. Probst C, Pape HC, Hildebrand F, Regel G, Mahlke L, Giannoudis P, et al. 30 years of polytrauma care: an analysis of the change in strategies and results of 4849 cases treated at a single institution. Injury. 2009:40(1):77-83.

163. Denk S, Weckbach S, Eisele P, Braun CK, Wiegner R, Ohmann JJ, et al. Role of hemorrhagic shock in experimental polytrauma. Shock. 2018:49(2):154-63.

164. Denk S, Wiegner R, Hones FM, Messerer DA, Radermacher P, Weiss M, et al. Early detection of junctional Adhesion Molecule-1 (JAM-1) in the circulation after experimental and clinical polytrauma. Mediators Inflamm. 2015;2015:463950.
165. Akscyn RM, Franklin JL, Gavrikova TA, Messina JL. Polytrauma-induced hepatic stress response and the development of liver insulin resistance. Biochim Biophys Acta. 2017;1863(10 Pt B):2672-9.

166. Darlington DN, Craig T, Gonzales MD, Schwacha MG, Cap AP, Dubick MA. Acute coagulopathy of trauma in the rat. Shock. 2013;39(5):440-6.

167. Rohban R, Pieber TR. Mesenchymal stem and progenitor cells in regeneration: tissue specificity and regenerative potential. Stem Cells Int. 2017;2017:5173732.

168. Peng W, Sun J, Sheng C, Wang Z, Wang Y, Zhang C, et al. Systematic review and meta-analysis of efficacy of mesenchymal stem cells on locomotor recovery in animal models of traumatic brain injury. Stem Cell Res Ther. 2015;6:47.

169. Hynes K, Bright R, Proudman S, Haynes D, Gronthos S, Bartold M. Immunomodulatory properties of mesenchymal stem cell in experimental arthritis in rat and mouse models: a systematic review. Semin Arthritis Rheum. 2016:46(1):1-19.

170. Mei L, Shen B, Ling P, Liu S, Xue J, Liu F, et al. Culture-expanded allogenic adipose tissue-derived stem cells attenuate cartilage degeneration in an experimental rat osteoarthritis model. PLOS ONE. 2017;12(4):e0176107.

171. Borger V, Bremer M, Ferrer-Tur R, Gockeln L, Stambouli O, Becic A, et al. Mesenchymal stem/stromal cell-derived extracellular vesicles and their potential as novel immunomodulatory therapeutic agents. Int J Mol Sci. 2017;18(7):1450.

172. Phinney DG, Pittenger MF. Concise review: MSC-derived exosomes for cell-free therapy. Stem cells (Dayton, Ohio). 2017;35(4):851-8.

173. Phinney DG, Di Giuseppe M, Njah J, Sala E, Shiva S, St Croix CM, et al. Mesenchymal stem cells use extracellular vesicles to outsource mitophagy and shuttle microRNAs. Nat Commun. 2015;6:8472.

174. Lin CS, Lin G, Lue TF. Allogeneic and xenogeneic transplantation of adipose-derived stem cells in immunocompetent recipients without immunosuppressants. Stem Cells Dev. 2012;21(15):2770-8.

175. Atoui R, Chiu RC. Concise review: immunomodulatory properties of mesenchymal stem cells in cellular transplantation: update, controversies, and unknowns. Stem Cells Transl Med. 2012;1 (3):200-5.

176. Faiella W, Atoui R. Immunotolerant properties of mesenchymal stem cells: updated review. Stem Cells Int. 2016;2016:1859567.

177. Lee FY, Chen KH, Wallace CG, Sung PH, Sheu JJ, Chung SY, et al. Xenogeneic human umbilical cord-derived mesenchymal stem cells reduce mortality in rats with acute respiratory distress syndrome complicated by sepsis. Oncotarget. 2017;8(28):45626-42.

178. Amann EM, Rojewski MT, Rodi S, Furst D, Fiedler J, Palmer A, et al. Systemic recovery and therapeutic effects of transplanted allogenic and xenogenic mesenchymal stromal cells in a rat blunt chest trauma model. Cytotherapy. 2018;20(2):218-31.

179. Gu LH, Zhang TT, Li Y, Yan HJ, Qi H, Li FR. Immunogenicity of allogeneic mesenchymal stem cells transplanted via different routes in diabetic rats. Cell Mol Immunol. 2015;12(4):444-55.

180. Ortiz LA, Dutreil M, Fattman C, Pandey AC, Torres G, Go K, et al. Interleukin 1 receptor antagonist mediates the antiinflammatory and antifibrotic effect of mesenchymal stem cells during lung injury. Proc Natl Acad Sci U S A. 2007;104(26):11002-7.

181. Curley GF, Hayes M, Ansari B, Shaw G, Ryan A, Barry F, et al. Mesenchymal stem cells enhance recovery and repair following ventilatorinduced lung injury in the rat. Thorax. 2012;67(6):496-501.

182. Drommelschmidt K, Serdar M, Bendix I, Herz J, Bertling F, Prager S, et al. Mesenchymal stem cell-derived extracellular vesicles ameliorate inflammation-induced preterm brain injury. Brain Behav Immun. 2017:60:220-32.

183. Cruz FF, Borg ZD, Goodwin M, Sokocevic D, Wagner DE, Coffey A, et al. Systemic administration of human bone marrow-derived mesenchymal stromal cell extracellular vesicles ameliorates aspergillus hyphal extractinduced allergic airway inflammation in immunocompetent mice. Stem Cells Transl Med. 2015;4(11):1302-16.

184. Zhang Y, Chopp M, Meng Y, Katakowski M, Xin H, Mahmood A, et al. Effect of exosomes derived from multipluripotent mesenchymal stromal cells on functional recovery and neurovascular plasticity in rats after traumatic brain injury. J Neurosurg. 2015;122(4):856-67. 
185. Lankford KL, Arroyo EJ, Nazimek K, Bryniarski K, Askenase PW, Kocsis JD. Intravenously delivered mesenchymal stem cell-derived exosomes target M2-type macrophages in the injured spinal cord. PLOS ONE. 2018;13(1):e0190358.

186. Ma Y, Dong L, Zhou D, Li L, Zhang W, Zhen Y, et al. Extracellular vesicles from human umbilical cord mesenchymal stem cells improve nerve regeneration after sciatic nerve transection in rats. J Cell Mol Med. 2019;23(4):2822-35

187. Zhang B, Wang M, Gong A, Zhang X, Wu X, Zhu Y, et al. HucMSCexosome mediated-Wnt4 signaling is required for cutaneous wound healing. Stem cells (Dayton, Ohio). 2015;33(7):2158-68.

188. Tanaka T, Hirose M, Kotobuki N, Tadokoro M, Ohgushi H, Fukuchi T, et al. Bone augmentation by bone marrow mesenchymal stem cells cultured in three-dimensional biodegradable polymer scaffolds. J Biomed Mater Res Part A. 2009;91(2):428-35.

189. Lam AT, Li J, Toh JP, Sim EJ, Chen AK, Chan JK, et al. Biodegradable poly-epsilon-caprolactone microcarriers for efficient production of human mesenchymal stromal cells and secreted cytokines in batch and fed-batch bioreactors. Cytotherapy. 2017;19(3):419-32.

190. Rady D, Mubarak R, Abdel Moneim RA. Healing capacity of bone marrow mesenchymal stem cells versus platelet-rich fibrin in tibial bone defects of albino rats: an in vivo study. F1000Research. 2018;7:1573.

191. Mousaei Ghasroldasht M, Matin MM, Kazemi Mehrjerdi H, NaderiMeshkin H, Moradi A, Rajabioun M, et al. Application of mesenchymal stem cells to enhance non-union bone fracture healing. J Biomed Mater Res Part A. 2019;107(2):301-11

192. Chen G, Fang T, Qi Y, Yin X, Di T, Feng G, et al. Combined use of mesenchymal stromal cell sheet transplantation and local injection of SDF-1 for bone repair in a rat nonunion model. Cell Transplant. 2016;25(10):1801-17.

193. Huang S, Xu L, Zhang Y, Sun Y, Li G. Systemic and local administration of allogeneic bone marrow-derived mesenchymal stem cells promotes fracture healing in rats. Cell Transplant. 2015;24(12):2643-55.

194. Muller CW, Hildebrandt K, Gerich T, Krettek C, van Griensven M, Rosado Balmayor E. BMP-2-transduced human bone marrow stem cells enhance neo-bone formation in a rat critical-sized femur defect. J Tissue Eng Regen Med. 2017;11(4):1122-31.

195. Chen Y, Zhao Y, Chen W, Xie L, Zhao ZA, Yang J, et al. MicroRNA-133 overexpression promotes the therapeutic efficacy of mesenchymal stem cells on acute myocardial infarction. Stem Cell Res Ther 2017:8(1):268

196. Li KC, Chang YH, Yeh CL, Hu YC. Healing of osteoporotic bone defects by baculovirus-engineered bone marrow-derived MSCs expressing MicroRNA sponges. Biomaterials. 2016;74:155-66.

197. Mir SA, Azam MQ, Al-Dakheel DA, Acharya S. Healing of experimentally created non-union of femur in rats using bone precursor cells from mesenchymal stem cells (MSCs). J Stem Cells. 2015;10(2):91-6.

198. Watanabe Y, Harada N, Sato K, Abe S, Yamanaka K, Matushita T. Stem cell therapy: is there a future for reconstruction of large bone defects? Injury. 2016:47(Suppl 1):S47-51.

199. Osugi M, Katagiri W, Yoshimi R, Inukai T, Hibi H, Ueda M. Conditioned media from mesenchymal stem cells enhanced bone regeneration in rat calvarial bone defects. Tissue Eng Part A. 2012;18(13-14):1479-89.

200. Zhou W, Liu Q, Xu B. Improvement of bone defect healing in rats via mesenchymal stem cell supernatant. Exp Ther Med. 2018;15(2):1500-4.

201. Qi X, Zhang J, Yuan H, Xu Z, Li Q, Niu X, et al. Exosomes secreted by human-induced pluripotent stem cell-derived mesenchymal stem cells repair critical-sized bone defects through enhanced angiogenesis and osteogenesis in osteoporotic rats. Int J Biol Sci. 2016;12(7):836-49.

202. Zhang S, Chu WC, Lai RC, Lim SK, Hui JH, Toh WS. Exosomes derived from human embryonic mesenchymal stem cells promote osteochondral regeneration. Osteoarthritis Cartilage. 2016;24(12):2135-40.

203. Zhang J, Liu X, Li H, Chen C, Hu B, Niu X, et al. Exosomes/tricalcium phosphate combination scaffolds can enhance bone regeneration by activating the PI3K/Akt signaling pathway. Stem Cell Res Ther. 2016;7(1):136

204. Zuo R, Liu M, Wang Y, Li J, Wang W, Wu J, et al. BM-MSC-derived exosomes alleviate radiation-induced bone loss by restoring the function of recipient BM-MSCs and activating Wnt/beta-catenin signaling. Stem cell Res Ther. 2019:10(1):30.

205. Russell WMS, Burch R. The principles of humane experimental technique. London: Methuen; 1959.

\section{Publisher's Note}

Springer Nature remains neutral with regard to jurisdictional claims in published maps and institutional affiliations.
Ready to submit your research? Choose BMC and benefit from:

- fast, convenient online submission

- thorough peer review by experienced researchers in your field

- rapid publication on acceptance

- support for research data, including large and complex data types

- gold Open Access which fosters wider collaboration and increased citations

- maximum visibility for your research: over 100M website views per year

At $\mathrm{BMC}$, research is always in progress.

Learn more biomedcentral.com/submissions 